\title{
Can the Scheldt River Estuary become hyperturbid?
}

\section{A model analysis of suspended sediment concentrations and transport in response to channel deepening}

\author{
Yoeri M. Dijkstra ${ }^{1}$ (D) . Henk M. Schuttelaars ${ }^{1}$. George P. Schramkowski ${ }^{1,2}$
}

Received: 17 December 2018 / Accepted: 23 May 2019 / Published online: 25 June 2019

(C) The Author(s) 2019

\begin{abstract}
We investigate the hypothesis by Winterwerp and Wang (Ocean Dyn 63:1279-1292, 2013) that channel deepening in the Scheldt River Estuary could lead to a large increase in suspended sediment concentrations, with subsequent severe consequences to primary production and navigation. To this end, we use an idealised model to investigate the long-term development of the sediment concentration under the uncertainty of future changes in model parameter values and channel deepening. The water motion is calibrated to recent conditions after which the sediment concentration is validated against long-term observations and is subsequently tested for a wide range of parameter settings and deepening scenarios. We also investigate the effect of anthropogenic dumping of dredged sediments in the estuary on the sediment concentration. Deepening the channel, but keeping all other model parameters the same, we find lower long-term average sediment concentrations in most of the estuary. Thereby, our results suggest that deepening in the Scheldt alone cannot lead to high sediment concentrations, and we suggest to reject the investigated hypothesis. Further study of uncertain model parameters reveals that an increase of the erosion parameter by an order of magnitude allows for the development of high concentrations of several tens of grams per liter near the bed in narrow turbidity zones. It is unknown whether such an increase of the erosion parameter can happen in the future, which stresses the importance of further research into the factors that can lead to a change of this parameter.
\end{abstract}

Keywords Scheldt $\cdot$ Hyperturbid $\cdot$ Sediment concentration $\cdot$ Deepening $\cdot$ Dredging $\cdot$ iFlow

\section{Introduction}

Suspended sediment dynamics is an important subject in the management of the Scheldt River Estuary, an estuary located in Belgium and Netherlands, see Fig. 1. Its importance is related to two factors. Firstly, primary production in the Scheldt estuary is to a large extent light limited due to suspended sediments (Kromkamp and Peene 1995). Secondly, dredging of fine sediments poses a significant cost in the maintenance of the navigation channel to the port of Antwerp (IMDC et al. 2013a). These issues related to fine sediments have

Responsible Editor: Bram C. van Prooijen

Yoeri M. Dijkstra

y.m.dijkstra@tudelft.nl

1 Delft Institute of Applied Mathematics, Delft University of Technology, Delft, Netherlands

2 Flanders Hydraulics Research, Antwerp, Belgium become increasingly important, as the long-term suspended sediment concentration has gradually increased by several tens of milligrams per liter over the last three decades in the Lower Sea Scheldt (km 55-95) and locally in the dry season in the Upper Sea Scheldt (> km 95) (Vandenbruwaene et al. 2016; Maris et al. 2017). At the same time, many anthropogenic changes to the estuary have been made, including extensive deepening of the channel for the mining of sand and improvement of navigability, the construction of locks and harbour basins and the development of intertidal area (see Van Braeckel et al. (2006) and Jeuken et al. (2007) for an overview). Moreover, sewage treatment has improved, thereby affecting the organic content of sediments and hence sediment properties (Maris and Meire 2017).

It has been suggested by Winterwerp and Wang (2013) that deepening in the long term may lead to the development of hyperturbid conditions in the Scheldt. According to their hypothesis, deepening causes a deformation of the tide that leads to an increasing import of fine sediment. The imported sediment leads to a reduction of the hydraulic drag, which supposedly leads to a further deformation of the 


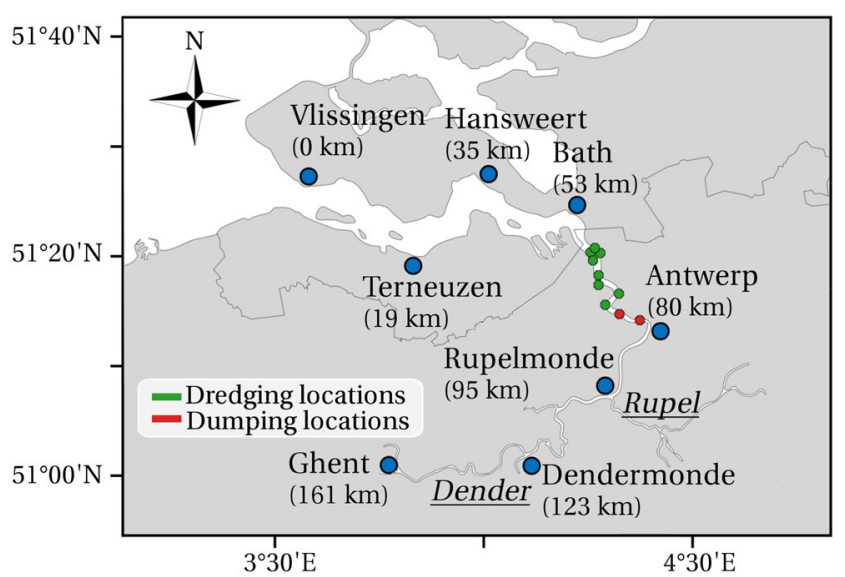

Fig. 1 Map of the tidal part of the Scheldt River from Vlissingen to Ghent. The Scheldt River is separated into the Dutch Western Scheldt $(<\mathrm{km} \mathrm{55)}$ and the Belgian Sea Scheldt ( $>\mathrm{km} \mathrm{55).} \mathrm{At} \mathrm{the} \mathrm{head} \mathrm{of}$ the estuary, the estuary is fed by water from the Upper Scheldt - Leie catchment. Two more tributaries are marked on the map in italics: the Dender and Rupel Rivers. Major locations where fine sediments are dredged and dumped in the Sea Scheldt are marked in green and red, respectively. Dredging and dumping also happens in the Western Scheldt but in smaller amounts, which are not considered in this study

tide and more sediment import, hence leading to a dramatic increase of the sediment concentration. This hypothesis is mainly based on examples of the Ems (Germany) and Loire (France) Rivers, which have become hyperturbid following decades of substantial channel deepening. Despite regular and long-term monitoring of sediment concentrations in the Scheldt River since the 1990s, it remains unclear whether the observed long-term trends are part of a development towards hyperturbidity (Vandenbruwaene et al. 2016; Maris et al. 2017). Statistical analysis of trends in the observations is not only complicated by a high degree of natural variability but also by memory effects, by which the sediment concentration depends on both the hydrodynamic conditions of several months in the past (Brouwer et al. 2018) and recent sediment dredging and dumping. Sediments dredged in the port of Antwerp are dumped back into the channel of the estuary a few kilometres upstream at rates that far exceed fluvial sediment supply. Hence, variations in the observed sediment concentrations are strongly influenced by the spatial and temporal variability in anthropogenic sediment dredging and dumping (e.g. Depreiter et al. 2015). While such memory effects and the effects of dredging and dumping are included in models, only a few model projections have been made of the response of sediment concentrations to channel deepening (Van Kessel et al. 2008) and dumping strategy (Van Kessel and Vanlede 2010; IMDC et al. 2013b). Some of the main challenges for such modelling studies are the long timescales at which the sediment concentration varies and large uncertainty in model parameters.
The goal of this study is to investigate if the Scheldt River can become hyperturbid as a response to channel deepening given the uncertainty in model parameters values. Moreover, we aim to gain insight into the processes and parameters that are most important to the sediment dynamics in the Scheldt. It should be stressed that we do not aim to explicitly describe variability on weekly, seasonal or yearly timescales in the past or future. Rather, we want to qualitatively capture the most important underlying physics, which allows us to extrapolate the modelled trends to uncertain future scenarios and the corresponding long-term average behaviour. To this end, we use the iFlow model, which is a width-averaged, idealised process-based model (Dijkstra et al. 2017). The model is used to directly compute the long-term equilibrium water motion and sediment concentration given prescribed geometry and forcing conditions, thus quickly showing the long-term response of the estuary to changing depth and model parameters. As the model is fast, it allows for extensive study of parameter sensitivity.

The set-up of the iFlow model used in this study is based on the model used by Dijkstra et al. (2019) to simulate the transition to hyperturbid conditions in the Ems after channel deepening. In addition, several processes thought to be essential for the sediment dynamics in the Scheldt River are added (Section 2). The model is calibrated against water levels for conditions of the year 2010 and modelled sediment concentrations are presented and compared to the long-term averaged observations (Section 3). Furthermore, the sensitivity of the results to the sediment settling velocity and erosion parameter is systematically analysed. Next, in Section 4, the model is applied to configurations with smaller and larger depths, investigating the response to past and possible future large-scale deepening. The physical processes explaining the results are analysed in Section 5. These processes are discussed in the context of the processes that act in the Ems estuary and in context of the model uncertainty in Section 6. This chapter ends with a summary of the main conclusions in Section 7.

\section{Model and methods}

\subsection{The iFlow model}

The model used in this study is the iFlow model (Dijkstra et al. 2017), a width-averaged idealised process-based model for water motion and sediment dynamics in estuaries and tidal rivers. The model solves approximations of the width-averaged continuity, momentum and sediment balance equations, and hence it resolves the flow and sediment concentration in the along-channel direction $x$, vertical direction $z$ and in time $t$. The model resolves a dynamic equilibrium state, which means that the water 
motion and sediment concentration may vary on the tidal timescale, but not on the subtidal timescale. The main model features and simplifications are discussed below.

The geometry of the model is represented by smooth fits of the measured width and depth, thereby ignoring the effect of small-scale bathymetric features on the estuary-scale dynamics. Additionally, it is assumed that the water surface elevation is small compared to the subtidal depth. These assumptions allow for the use of scaling and perturbation methods, which lead to systems of mathematical equations that can be solved at low computational costs and allow for making a decomposition of the water motion and sediment transport into contributions by individual physical forcing mechanisms. For a further detailed description of the basic model equations and solution methods, we refer to Dijkstra et al. (2017).

The effects of turbulence in the model are parametrised by using an eddy viscosity, eddy diffusivity and a quasiquadratic bed friction formulation (see Appendix A or Dijkstra et al. (2019) for a mathematical description). The eddy viscosity and diffusivity are assumed to be depth uniform and constant in time but depend on the tideaveraged, depth-averaged flow velocity and depth. The quasi-quadratic bed friction formulation is obtained by linearising the bed friction but allowing the linearised bed friction coefficient to depend on the tide-averaged, depthaveraged velocity. The model furthermore accounts for the effects of sediment-induced damping of turbulence, which represents the reduction in turbulent mixing due to vertical density stratification by sediment. This is accounted for by reducing the eddy viscosity and eddy diffusivity using tide-averaged, depth-averaged damping functions based on the formulations of Munk and Anderson (1948). The bed friction is reduced by using a tide-averaged damping function of the Richardson number, following e.g. Adams and Weatherly (1981). The turbulence model is calibrated using two coefficients: a dimensionless roughness height $z_{0}^{*}$ that affects the eddy viscosity, eddy diffusivity and bed friction, and a background shear $u_{z \text {, min }}$ that controls the strength of sediment-induced turbulence damping.

Sediment is modelled assuming a single class of non-cohesive sediment. The settling velocity is assumed constant but may be reduced due to effects of hindered settling, which represents a decreased sediment settling velocity due to particle-particle interactions when sediment concentrations are high. At the bed, the subtidal stock of sediment available for erosion is accounted for by the model. Erosion or resuspension of sediment from the bed occurs through an erosion law inspired by the Partheniades formulation (e.g. Kandiah 1974) but without a critical shear stress:

$E=M|\tau| f$.
Here, $E$ is the erosion rate, $M$ is an erosion parameter (in $\mathrm{s} / \mathrm{m}), \tau$ is the bed shear stress and $f$ is the erodibility, which is a measure for the amount of available sediment on the bed and takes a value between 0 and 1 . In regions with $\mathrm{f}<1$, the low availability of sediment limits the erosion (supply limited). In regions where $\mathrm{f}=1$ is predicted, excess sediment is available in the bed, and erosion is limited instead by bottom stress (erosion limited). This will locally result in continual net deposition of sediment at the bed in equilibrium (see Section 5.1 for additional explanation of erodibility).

Salinity is modelled diagnostically, by setting a prescribed salinity gradient that is fitted to observations. The salinity is assumed to be depth uniform and constant over the tidal cycle, approximating conditions in very well-mixed estuaries.

The model is forced by constant $M_{2}$ and $M_{4}$ tidal amplitudes and a subtidal depth-averaged sediment concentration at the mouth. Furthermore, constant river discharges are prescribed at the head of the estuary and at the confluences with the Dender and Rupel tributaries (see Fig. 1), and a discharge-dependent fluvial supply of sediments is prescribed at the discharge locations. The inflow of water and sediment from tributaries is a new feature in iFlow, and its mathematical implementation is described in Appendix B.

Together, the equations form a non-linear set that is solved iteratively using the procedure summarised in Fig. 2. The solution procedure consists of a combination of algebraic relations and numerical and analytical solution methods, where analytical methods are used for speed and accuracy whenever possible. The numerical computation of the water level and erodibility are done using a second-order finite difference method on an equidistant grid with 250 grid cells. All vertical profiles are computed analytically and do not require a numerical grid. In the time dimension, the model is solved in terms of a constant subtidal component and $M_{2}$ and $M_{4}$ tidal constituents (i.e. spectral method).

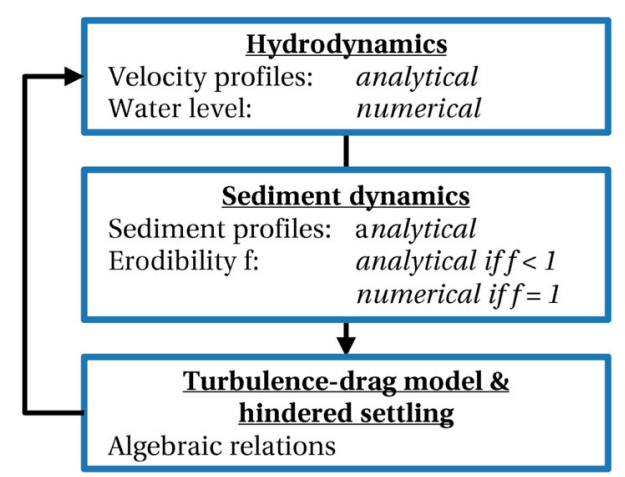

Fig. 2 Summary of the model components (boxes) and the solution methods (in italics), indicating the iteration over the components by arrows. Figure modified from Dijkstra et al. (2019) 
Hence, time stepping routines are not necessary and there is no time step or spin-up time.

\subsection{Description of the Scheldt River Estuary and model forcing}

The Scheldt River Estuary is modelled as a single channel from the mouth at Vlissingen to the tidal weir and locks at Ghent, $161-\mathrm{km}$ upstream. Tidal propagation into the tributaries (see Fig. 1) is not explicitly taken into account. The width of the Scheldt in the model is represented by the average of the width at the surface at high and low water and is fitted by a smooth function. The width-averaged depth of the Scheldt is derived by dividing the cross-sectional area by the width at high and low water, subsequently subtracting the average water level elevation at high and low water and then taking the average. The resulting depth is fitted using a smooth polynomial function, see Fig. 3 . The procedure for deriving the depth is slightly different to that used by Brouwer et al. (2018) for the Scheldt and is used because, in contrast to the procedure of Brouwer et al. (2018), it can be repeated for the historical high and low water data used in Section 4.

The model is forced by an $M_{2}$ and $M_{4}$ tide at the mouth, representing year-averaged tidal conditions, obtained using a complex demodulation analysis (e.g. Jalón-Rojas et al. 2016) on the 10-min resolution tidal elevation observations at Vlissingen for 2009. This yields an $M_{2}$ amplitude of 1.81 $\mathrm{m}$ and an $M_{4}$ amplitude of $0.16 \mathrm{~m}$ with a relative phase difference between the $M_{2}$ and $M_{4}$ tide of -4 degrees. Fresh water discharges into the Scheldt at three locations: at the upstream boundary from the Upper Scheldt - Leie system, at Dendermonde (km 123) from the Dender tributary and at Rupelmonde (km 95) from the Rupel tributary. The Rupel has several tributaries itself and its fresh water discharge equals the sum of the discharges of its tributaries. We use the average discharge for a year, summer (Jul-Sep) and winter
(Jan-Mar) averaged over the years 1971-2017 (data from www.waterinfo.be), see Table 1.

Several methods can be used to estimate the fluvial sediment supply as a function of the river discharge. Vanlierde et al. (2016) present a simple regression model relating the instantaneous sediment concentration from 7 hourly measurements to the instantaneous river discharge for data of 2015. However, the number of data points and quality of the fit are low, so that this method is not reliable for estimating the long-term sediment supply. Therefore, we choose to correlate the year-averaged estimated fluvial sediment supply and year-averaged river discharge of each tributary. The fluvial sediment supply is estimated using sediment concentration data obtained from weekly samples near the river bank between 2001 and 2015 (data from Vanlierde et al. $(2014,2016)$ and Vandenbruwaene et al. 2017), see Fig. 4. A linear fit is chosen over more conventional power relations to prevent over-fitting of the small amount of data. The obtained relations for the fluvial sediment load (in $\mathrm{kg} / \mathrm{s}$ ) read

$$
\begin{aligned}
Q_{\text {sed, Upper Scheldt-Leie }} & =0.080 Q_{\text {Upper Scheldt-Leie }}, \\
Q_{\text {sed, Dender }} & =0.088 Q_{\text {Dender }}, \\
Q_{\text {sed, Rupel }} & =0.035 Q_{\text {Rupel }}
\end{aligned}
$$

A comparison of 7-hourly and weekly sediment measurements by Plancke et al. (2017) indicates that fits of Eqs. 2 and 4 likely underestimate the sediment supply per tributary by a factor 3 to 6 ( 3.5 for the entire estuary for 2016). However, as the 7-hourly data are only available for a few years, we base our fits on the weekly data. A sensitivity study (not presented here) showed that increasing the fluvial supply by a factor 3 to 6 does not notably change the results presented in this study.

At the seaward boundary, a depth- and tide-averaged sediment concentration $c_{\text {sea }}=0.06 \mathrm{~kg} / \mathrm{m}^{3}$ is prescribed, based on observations. The sediment settling velocity $w_{s, 0}$

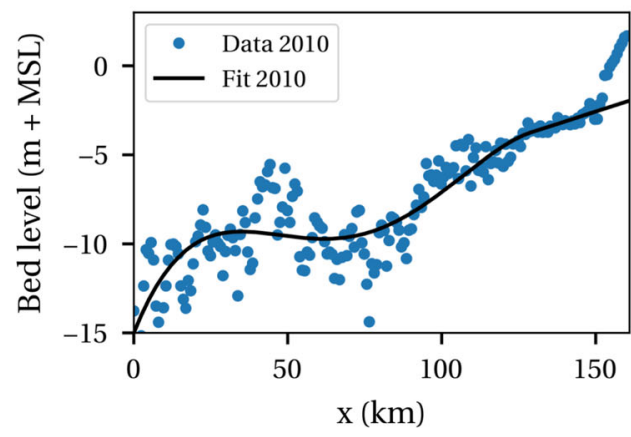

(a) Bed level

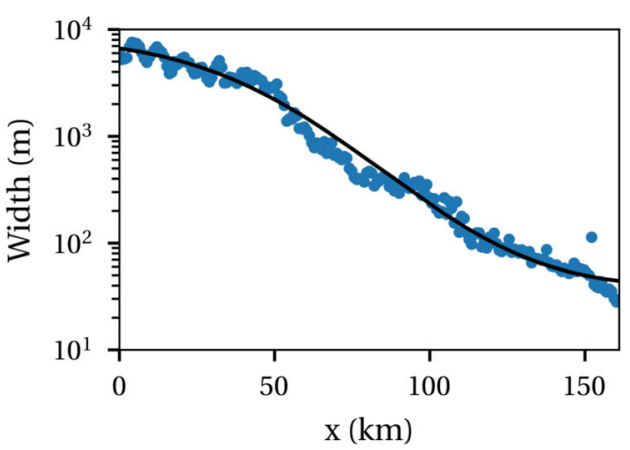

(b) Width

Fig. 3 Bed level relative to mean sea level at Vlissingen $(x=0)$ and width of the Scheldt in 2010. Dots represent the observations. The lines are the smooth fits of the data used in the model 
Table 1 Discharge averaged over the year, summer (Jul-Sep) and winter (Jan-Mar) averaging over 1971 to 2017 and the percentage of river discharge per tributary

\begin{tabular}{lllll}
\hline & Discharge $\left(\mathrm{m}^{3} / \mathrm{s}\right)$ & Upper Scheldt-Leie $(\mathrm{km} \mathrm{161)}$ & Dender $(\mathrm{km} \mathrm{123)}$ & Rupel $(\mathrm{km}$ 95) \\
\hline Average & 110 & $32 \%$ & $10 \%$ & $58 \%$ \\
Summer & 56 & $27 \%$ & $8 \%$ & $65 \%$ \\
Winter & 170 & $36 \%$ & $11 \%$ & $53 \%$ \\
\hline
\end{tabular}

The contribution of the Rupel equals the sum of the contributions of its tributaries. Data from http://www.waterinfo.be

is set to $2 \mathrm{~mm} / \mathrm{s}$ based on the average settling velocity of the flocs, as measured during a 1-day campaign in February 2005 near the port of Antwerp (IMDC et al. 2007). The erosion parameter $M$ is calibrated in such a way that the model captures the order of magnitude of the maximum surface concentration observed in the estuary in 2010. The sensitivity of the model results to $w_{s, 0}$ and $M$ is investigated in Section 3.3. The default values of the model parameters are given in Table 2.

Salinity is represented in the model by a depth uniform and tide-averaged profile along the estuary, according to Talke et al. (2009)

$s=\frac{s_{\text {sea }}}{2}\left(1-\tanh \left(\frac{x-x_{c}}{x_{l}}\right)\right)$,

where the model parameters are fitted surface salinity data gathered within the MWTL (Western Scheldt) and OMES (Sea Scheldt) programmes between 1982 and 2016. This yields $s_{\text {sea }}=31 \mathrm{psu}, x_{l}=32 \mathrm{~km}$. The salt-intrusion length scale $x_{c}$ is related to the discharge as $x_{c}=\alpha\left(\frac{Q}{Q_{\text {average }}}\right)^{\beta}$, where $\alpha=41 \mathrm{~km}, \beta=-0.24$ and $Q_{\text {average }}=110 \mathrm{~m}^{3} / \mathrm{s}$.

\subsection{Dredging and dumping}

Dredging of fine sediments predominantly takes place at eight sills, lock entrances and harbour basins located

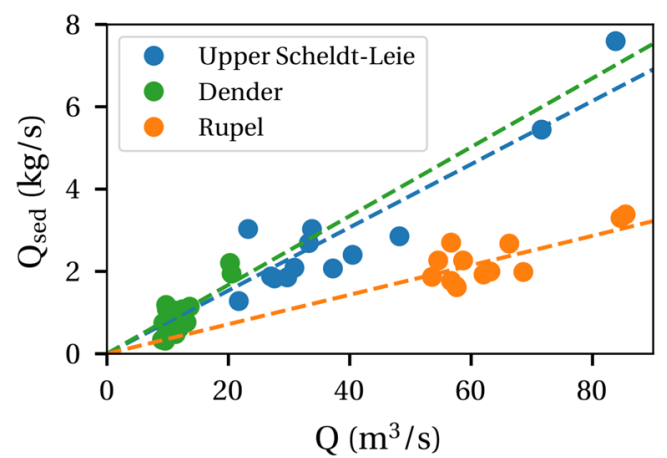

Fig. 4 Estimated year-averaged fluvial sediment supply $Q_{\text {sed }}$ for the three major tributaries as a function of the year-averaged discharge per tributary. Each dot represents a year between 2001 and 2015 (2012 and 2014 are missing). The dotted lines are linear least-squares fits through the data. Estimates of $Q_{\text {sed }}$ are from Vanlierde et al. (2014), Vanlierde et al. (2016), and Vandenbruwaene et al. (2017) between $\mathrm{km} 60$ and 71, see the green dots in Fig. 1 (IMDC et al. 2013a). All of the dredged fine sediments are dumped back into the navigation channel a few kilometres upstream at Punt van Melsele ( $\mathrm{km} \mathrm{73)}$ and Plaat van Boomke / Oosterweel ( $\mathrm{km} \mathrm{78}$ ), see the red dots in Fig. 1. Exceptions are the years 1990-2000, when 300,000 tons of dry fine sediment was removed from the estuary. Figure 5 shows the amount of dredging and dumping in the Western Scheldt $(<\mathrm{km} \mathrm{55)}$ and Sea Scheldt $(>\mathrm{km} \mathrm{55)}$ in tons of dry sediment per year, compared to the estimated fluvial fine sediment supply from all tributaries (data from IMDC et al. (2013a), Vandenbruwaene et al. (2016) and Barneveld et al. 2018). This shows that the sediment source due to dumping exceeds the fluvial supply by an order of magnitude.

As harbour basins, sills and shallow areas are not explicitly resolved by the model, sediment deposition is not fully resolved. Hence, if dredging were taken into account by imposing a sink in the model, sediment would be extracted while an insufficient amount is deposited according to the model, leading to negative sediment concentrations. Therefore we do not take dredging into account in the model, but we do consider dumping. Dumping of sediment is represented using continuous point sources at $\mathrm{km} 73$ and 78 with rates of 60.5 and $98.5 \mathrm{~kg} / \mathrm{s}$, respectively, corresponding to the average dumping rate in the Sea Scheldt between 2001 and 2015. Dumping of sediment in the Western Scheldt is neglected as the dumping volumes are relatively small, especially when considering the much larger volume of the Western Scheldt.

\section{Results and sensitivity of the 2010 case}

\subsection{Model calibration}

The $M_{2}$ water level is calibrated to observations by varying the roughness parameter until a best fit to data is found; the optimal dimensionless roughness value is $z_{0}^{*}=5 \cdot 10^{-4}$. The resulting $M_{2}$ and $M_{4}$ water level amplitude and phase and cross-sectionally averaged velocity amplitude are plotted in Fig. 6. The model results are compared to water level observations from 2009 and velocity observations from one 13-h cross-section measurement in 2009 (data from 
Table 2 Default model parameters

\begin{tabular}{llll}
\hline & Parameter & & Value \\
\hline Hydrodynamics & $A^{0}$ & $M_{2}$ water level amplitude at x=0 & $1.81 \mathrm{~m}$ \\
& $A^{1}$ & $M_{4}$ water level amplitude at $\mathrm{x}=0$ & $0.16 \mathrm{~m}$ \\
& $\phi^{1}$ & $M_{4}$ water level phase relative to $M_{2}$ tide at $\mathrm{x}=0$ & $-4 \mathrm{deg}$ \\
Sediment & $c_{\text {sea }}$ & Depth-averaged subtidal concentration at x=0 & $0.06 \mathrm{~kg} / \mathrm{m}^{3}$ \\
& $K_{h}$ & Horizontal eddy diffusivity & $100 \mathrm{~m}^{2} / \mathrm{s}$ \\
& $M$ & Erosion parameter & $7 \cdot 10^{-4} \mathrm{~s} / \mathrm{m}^{2} \mathrm{~mm} / \mathrm{s}$ \\
Turbulence & $w_{s, 0}$ & Clear-water settling velocity & $100 \mathrm{~kg} / \mathrm{m}^{3}$ \\
& $c_{\text {gel }}$ & Gelling concentration & 1 \\
& $\sigma_{\rho}$ & Prandtl-Schmidt number $\left(=A_{v} / K_{v}\right.$ for $\left.R i=0\right)$ & $0.031 / \mathrm{s}$ \\
\hline
\end{tabular}

Rijkswaterstaat, HIC and Flanders Hydraulics Research). The data are analysed using complex demodulation after which the average amplitude and phase over the year is used. The overall observed patterns for the $M_{2}$ tidal amplitude are reproduced, but the $M_{4}$ tidal amplitude is overestimated locally by more than a factor two. The tidal phases of both the $M_{2}$ and $M_{4}$ tide are reproduced well.

The modelled $M_{2}$ tidal velocity shows two maxima near $\mathrm{km} 20$ and $\mathrm{km} 120$ and minima at the mouth, $\mathrm{km} 70$ and at the landward boundary, where the tide vanishes. The same pattern is observed in the measurements and the overall magnitude of the modelled velocity corresponds to the measurements. The modelled $M_{4}$ velocity increases up to $\mathrm{km} 140$ before it vanishes at the landward boundary. While a maximum in the $M_{4}$ velocity in the upstream part of the estuary is also found in the measurements, measured velocities are much lower than the modelled velocities, similar to what was found for the tidal elevation.

\subsection{Sediment concentration compared to data}

In order to verify the performance of the model, we compare the modelled sediment concentration in the
2010 case using default parameter settings and the year-averaged discharge (Table 2) to long-term averages of sediment concentration observations. Observations of surface sediment concentrations were collected between 1990 and 2015 within the MWTL (Western Scheldt) and OMES (Sea Scheldt) programmes. The data was gathered bi-weekly to monthly, independent of the tidal conditions, by taking water samples (see Maris and Meire (2017) for details on the OMES programme). Observations of the depth-averaged sediment concentration were collected in the period 2001-2015 as part of the OMES programme and are based on pump samples at different depths with approximately equal coverage of the entire water column (Vandenbruwaene et al. 2016). Finally, we have included data from four permanent optical measurement stations at a depth roughly halfway the average water depth, hence roughly representing depth-averaged concentrations. Variations on timescales smaller than one $M_{2}$ tidal cycle have been filtered from the observations (see the caption of Fig. 7 for more information per station).

Modelled subtidal sediment concentrations for a yearaveraged discharge $\left(Q=110 \mathrm{~m}^{3} / \mathrm{s}\right)$ are plotted in Fig. 7 . First, we compare the observations and model results

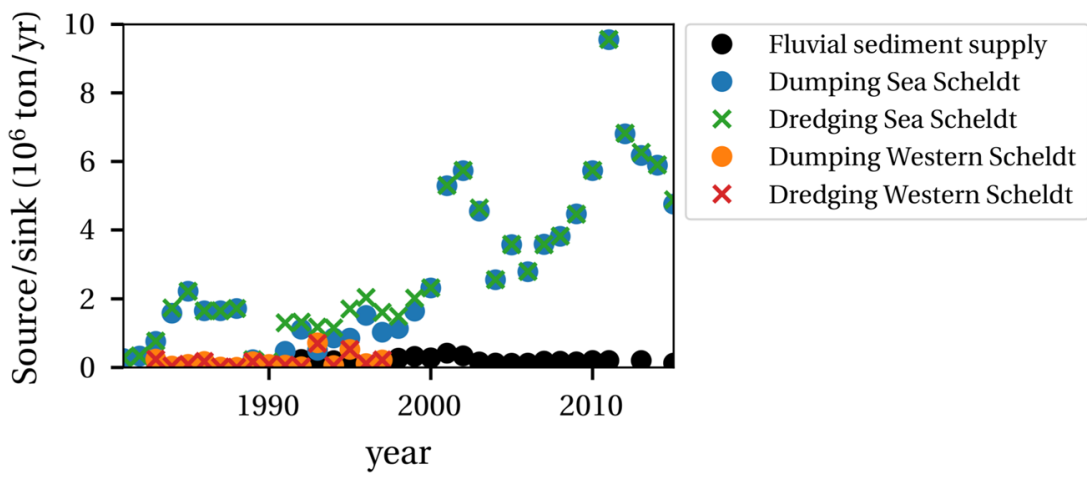

Fig. 5 Reported dredging and dumping of fine sediments in the Western Scheldt $(<\mathrm{km} 55)$ and Sea Scheldt $(>\mathrm{km} 55)$ per year in Million ton/yr, compared to the estimated yearly fluvial sediment supply from all tributaries combined. Data on dredging and dumping are from IMDC et al. (2013a), Vandenbruwaene et al. (2016), and Barneveld et al. (2018) 


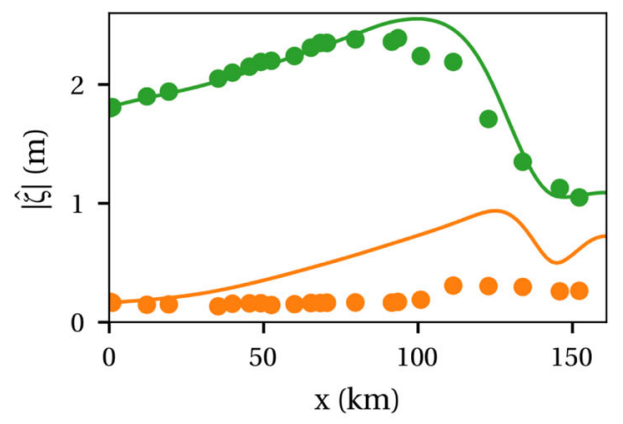

(a) Water level amplitude

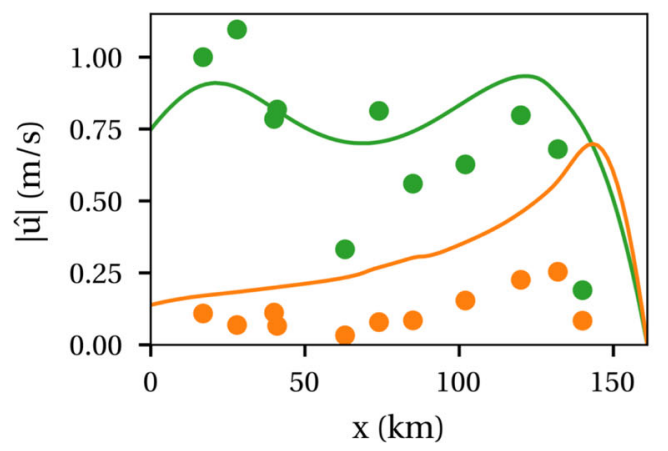

(c) Cross-sectionally averaged velocity amplitude

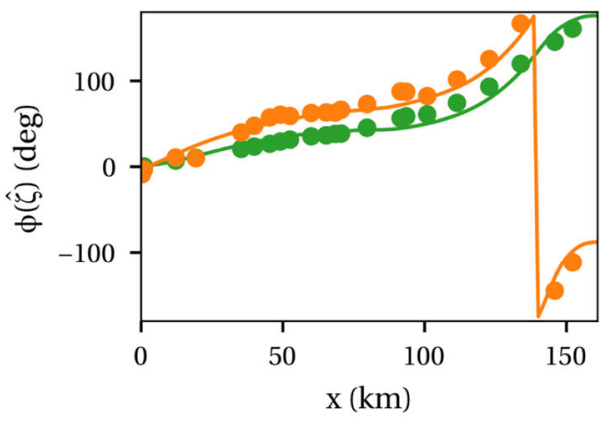

(b) Water level phase

Fig. 6 Water level amplitude (a) and phase (b) and cross-sectionally averaged velocity amplitude (c) for the $M_{2}$ tide (green) and $M_{4}$ tide (red). The model results are represented by the solid lines and compared to year-averaged observations from 2009 in dots

without dumping of sediment (Fig. 7a). At the water surface, the model reproduces the location of the ETM at km 115, with a concentration of around $0.11 \mathrm{~kg} / \mathrm{m}^{3}$, similar to the observations. A second ETM is found in the model around $\mathrm{km} 150$ with a surface concentration of $0.23 \mathrm{~kg} / \mathrm{m}^{3}$. The measurements are not conclusive on whether the second ETM exists. The OMES surface data only shows a very narrow peak, which may be an artefact. On the other hand, the continuous turbidity measurements at Melle (sensor 1 $\mathrm{m}$ above the bed) show concentrations of around $0.3-0.4$ $\mathrm{kg} / \mathrm{m}^{3}$, indicating elevated concentrations could be realistic. The depth-averaged concentration observations show an ETM around $\mathrm{km} 75$ and 100, different to what is observed at the surface. These ETM are not captured by the model, which shows the same patterns as the surface concentration. When considering the model with dumping of sediment (Fig. 7b), the main difference is in the depth-averaged concentration. The model results now display an ETM at $\mathrm{km} \mathrm{85}$, approximately corresponding to the observations on both location and order of magnitude of the sediment concentration. The location of the ETM does not correspond exactly to the dumping location, indicating that sediment concentrations are not just elevated because of the dumping of sediment but because sediment is trapped by the flow some distance upstream from the dumping location.
As the highest sediment concentrations typically occur during the relatively dry summer months, we also verify the model results using the average summer river discharge ( $\left.Q=56 \mathrm{~m}^{3} / \mathrm{s}\right)$ to measurements taken in the summer $(\mathrm{Jul}-$ Sep), see Fig. 8. The modelled ETM at the surface moves a few kilometers upstream to $\mathrm{km} 120$ with a concentration of $0.12 \mathrm{~kg} / \mathrm{m}^{3}$ without dumping (Fig. 8a) and $0.18 \mathrm{~kg} / \mathrm{m}^{3}$ with dumping (Fig. 8b), corresponding to the large-scale trends observed in the measurements. The modelled surface ETM around $150 \mathrm{~km}$ decreases in magnitude to values that match OMES observations. Similar to the case with year-averaged discharge, the depth-averaged concentration observations are qualitatively reproduced in terms of the ETM location and magnitude only if dumping is included in the model. The depth-averaged ETM is located around km 100 with a concentration around $0.27 \mathrm{~kg} / \mathrm{m}^{3}$.

\subsection{Sensitivity to the settling velocity and erosion parameter}

The characteristics of the sediment in the model are predominantly determined by the clear-water settling velocity $w_{s, 0}$ and erosion parameter $M$. Both parameters are highly uncertain and subject to natural variation. We therefore test the model sensitivity for settling velocities between 0.5 and 

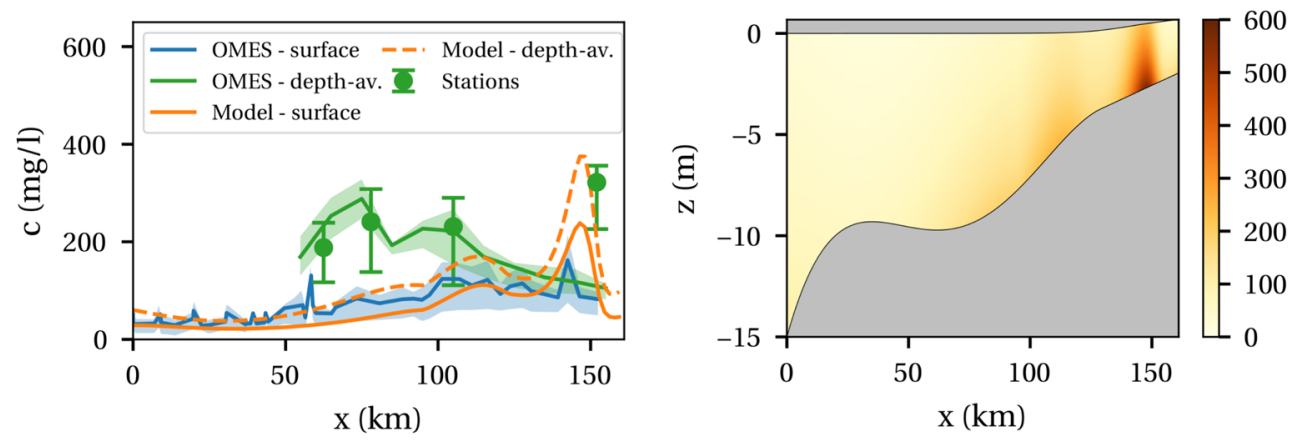

(a) Without dumping
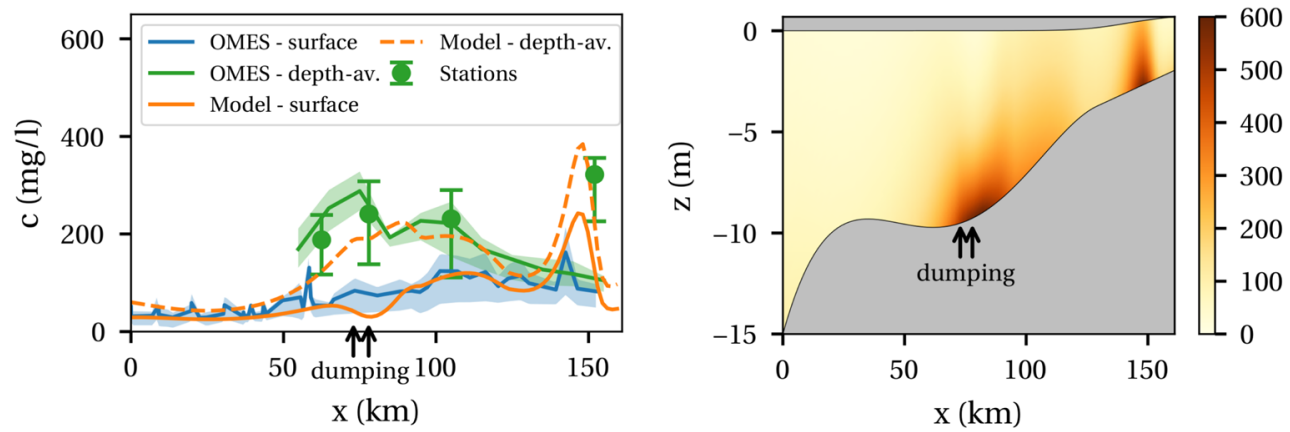

(b) With dumping

Fig. 7 Modelled subtidal sediment concentrations $(\mathrm{mg} / \mathrm{l})$ at the surface, depth-averaged and in an along-channel cross-section for a year-averaged discharge $\left(Q=110 \mathrm{~m}^{3} / \mathrm{s}\right)$ with (a) and without (b) dumping of sediment. The modelled sediment concentration results are also plotted in the along-channel vertical plane. The modelled sediment concentrations at the surface (orange solid line) are compared to the 1990-2015 average of surface MWTL/OMES data (blue line: mean, blue band: $25-75$ percentile). Depth-averaged modelled concentrations (orange dashed line) are compared to the 2010-2015

$4 \mathrm{~mm} / \mathrm{s}$ and erosion parameters between $10^{-4}$ and $10^{-1}$ $\mathrm{s} / \mathrm{m}$, keeping all other settings the same. Model results including dumping of sediment for the average and summer discharge conditions are shown in Fig. 9. For both discharge conditions, we find one ETM downstream of km 120 and one landward of $\mathrm{km} \mathrm{130.} \mathrm{Therefore,} \mathrm{the} \mathrm{figure} \mathrm{shows}$

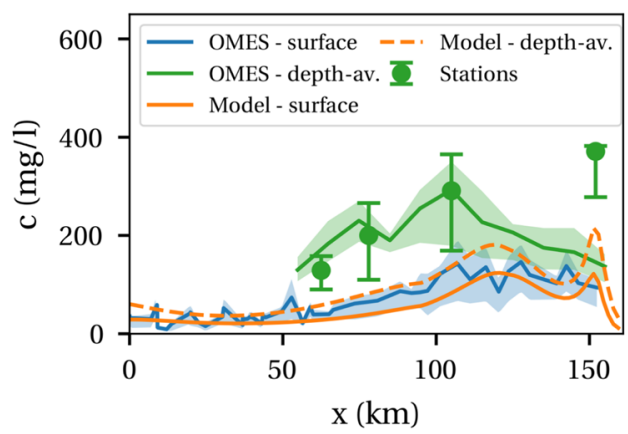

(a) Without dumping

Fig. 8 Modelled subtidal sediment concentrations at the surface and depth-averaged for summer discharge conditions $\left(Q=56 \mathrm{~m}^{3} / \mathrm{s}\right)$ with (a) and without (b) dumping. Model results are compared to the average of OMES data representative of the depth-averaged (green line: mean, green band: 25-75 percentile, data copied from Maris and Meire 2017). The green dots and error bars represent the average and 25-75 percentile values of tide-filtered data from continuous optical stations at: Boei 84/Lillo Upper (km 63, Sep. 2005-2017, $3.75 \mathrm{~m}$ above the bed), Oosterweel Upper (km 78, 2001-2017, $4.5 \mathrm{~m}$ above the bed), Driegoten ( $\mathrm{km}$ 105, 2009-May 2016, $3 \mathrm{~m}$ below the surface) and Melle

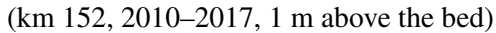

the maximum depth-averaged, subtidal sediment concentration seaward of $\mathrm{km} 125$ and landward of $\mathrm{km} 125$ for each combination of $w_{s, 0}$ and $M$.

For average discharge conditions in the ETM seaward of km 125 (Fig. 9a), the highest depth-averaged sediment concentrations are approximately $2 \mathrm{~g} / \mathrm{l}$ and are found for

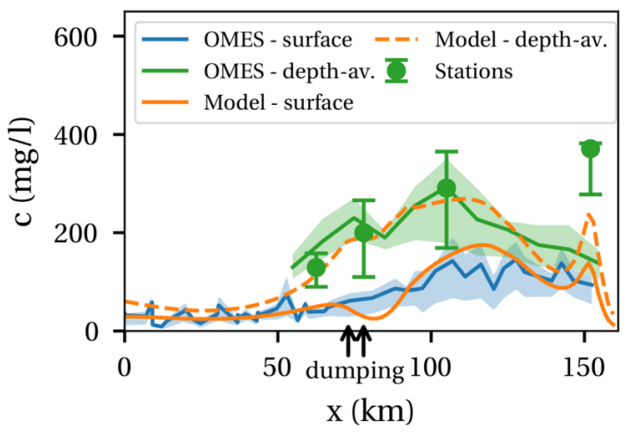

(a) With dumping

average of observations obtained during the summer and winter months. See Fig. 7 for references to the observations 


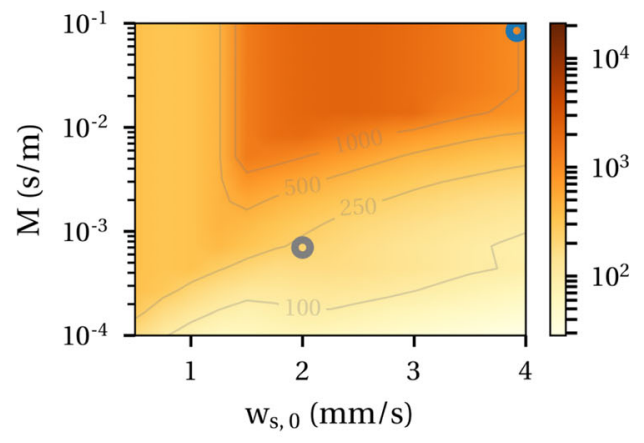

(a) Average conditions $\left(Q=110 \mathrm{~m}^{3} / \mathrm{s}\right)$ seaward of $\mathrm{km}$ 125.

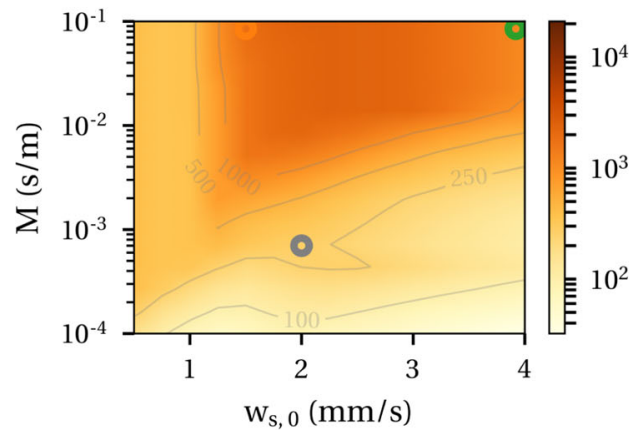

(c) Summer conditions $\left(Q=56 \mathrm{~m}^{3} / \mathrm{s}\right)$ seaward of $\mathrm{km}$ 125.

Fig. 9 Maximum depth-averaged sediment concentration (indicated by the colours, in $\mathrm{mg} / \mathrm{l}$ ) in the area seaward and landward of $\mathrm{km} 125$ for a range of values of the settling velocity $w_{s, 0}$ and erosion parameter $M$ and for average and summer discharge conditions. The grey

$M>10^{-2} \mathrm{~s} / \mathrm{m}$ and $w_{s, 0}$ between 2 and $3 \mathrm{~mm} / \mathrm{s}$. The ETM landward of km 125 (Fig. 9b) shows the highest depthaveraged concentrations up to $9 \mathrm{~g} / \mathrm{l}$ for a combination of $M>10^{-2} \mathrm{~s} / \mathrm{m}$ and large $w_{s, 0}$. High settling velocities correspond to large vertical gradients in the sediment concentration. As a result, the maximum concentration near the bed is $22 \mathrm{~g} / \mathrm{l}$, which is significantly larger than the depth-averaged concentration.

For summer discharge conditions, the ETM seaward of $\mathrm{km} 125$ (Fig. 9c) shows the same behaviour for varying $M$ and $w_{s, 0}$ as for average discharge conditions. However, depth-averaged concentrations are now up to approximately $1 \mathrm{~g} / \mathrm{l}$ and therefore lower than for average discharge conditions. The ETM landward of km 125 (Fig. 9d) shows a different behaviour for varying $M$ and $w_{s, 0}$ within the tested range. The highest depth-averaged concentrations of approximately $11 \mathrm{~g} / \mathrm{l}$ are found for the largest values of $M$ and $w_{s, 0}$ around $1-1.5 \mathrm{~mm} / \mathrm{s}$. Near the bed, maximum concentrations of up to $40 \mathrm{~g} / \mathrm{l}$ are found in the ETM landward of $\mathrm{km} 125$.

While the ETM seaward of $\mathrm{km} 125$ is strongly affected by dumping of sediment, high concentrations can also be attained in this ETM if dumping is excluded from the

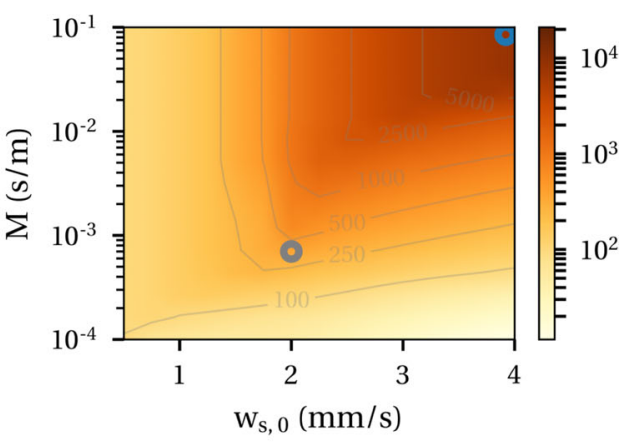

(b) Average conditions $\left(Q=110 \mathrm{~m}^{3} / \mathrm{s}\right)$ landward of $\mathrm{km}$ 125.

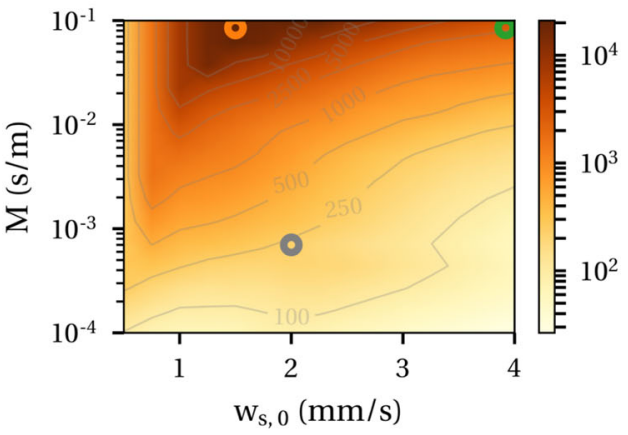

(d) Summer conditions $\left(Q=56 \mathrm{~m}^{3} / \mathrm{s}\right)$ landward of $\mathrm{km}$ 125 .

lines are iso-concentration lines. The grey circle indicates the default case (Table 2), the coloured circles correspond to along-channel concentration profiles plotted in Fig. 10

model (not shown). This confirms the earlier observation that this ETM corresponds to a sediment trapping location, not just a plume of dumped sediment. Without dumping, concentrations in the ETM seaward of $\mathrm{km} 125$ would be similar as in Fig. $9 \mathrm{a}$ and $\mathrm{c}$ for $w_{s, 0}$ approximately $>3 \mathrm{~mm} / \mathrm{s}$; dumping strongly affects the concentration in this ETM for $w_{s, 0}<3 \mathrm{~mm} / \mathrm{s}$. The ETM landward of $\mathrm{km} 125$ is not strongly affected by dumping for any combination of $M$ and $w_{s, 0}$.

To further illustrate the along-channel distribution of sediment for some of the cases with higher erosion parameter, Fig. 10 shows along-channel near-bed sediment concentrations for three situations, all with $M=0.1 \mathrm{~s} / \mathrm{m}$ and different $Q$ and $w_{s, 0}$, as marked by the coloured circles in Fig. 9 (here near-bed concentration is defined as that found at the bottom boundary in the model). For all three plotted cases, the sediment concentration locally exceeds $10 \mathrm{~g} / \mathrm{l}$, concentrated around two ETM. Between these ETM concentrations are much lower with values around 100-200 $\mathrm{mg} / \mathrm{l}$. Even though concentrations are moderate in a large part of the estuary, we call these conditions hyperturbid, as the sediment concentrations are high over an along-channel distance of several tens of kilometers and have a visible 


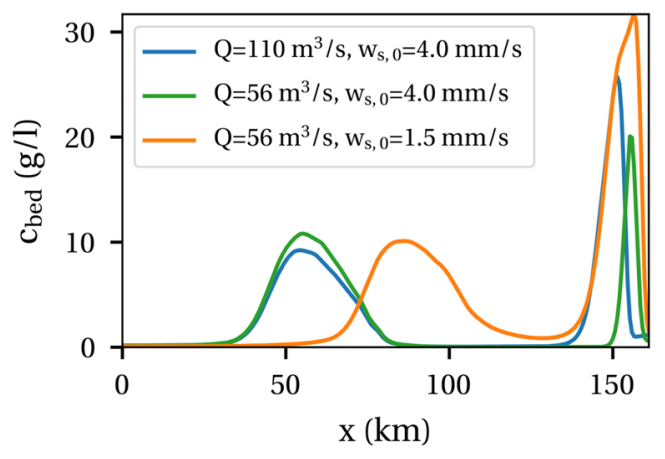

Fig. 10 Modelled along-channel distribution of the subtidal sediment concentrations near the bed for three cases: (1) $M=0.1 \mathrm{~s} / \mathrm{m}, w_{s, 0}=4$ $\mathrm{mm} / \mathrm{s}$ and average discharge, (2) $M=0.1 \mathrm{~s} / \mathrm{m}, w_{s, 0}=4 \mathrm{~mm} / \mathrm{s}$ and summer discharge and (3) $M=0.1 \mathrm{~s} / \mathrm{m}, w_{s, 0}=1.5 \mathrm{~mm} / \mathrm{s}$ and summer discharge

effect on the water motion (not shown). Thus, hyperturbid conditions can occur in our model of the Scheldt but only for values of $M$ 10-100 times the default value based on calibration.

\section{Response to channel deepening}

\subsection{Water level and sediment concentration}

Over the last decades, the Scheldt River Estuary has become deeper due to sand mining and channel deepening. Measurements and smoothed approximations of the widthaveraged depth in 1960 and 2010 are plotted in Fig. 11. Inspired by the along-channel pattern of deepening in the past, we define depth profiles of the form

$H_{\alpha}=(1-\alpha) H_{1960}+\alpha H_{2010}$

where $H_{1960}, H_{2010}$ are the fitted depth profiles of 1960 and 2010 and $\alpha$ is a bed-profile parameter. For $\alpha=0$, we obtain the depth of 1960; for $\alpha=1$, we obtain the depth of 2010; and for $\alpha>1$, we obtain a depth larger than in 2010

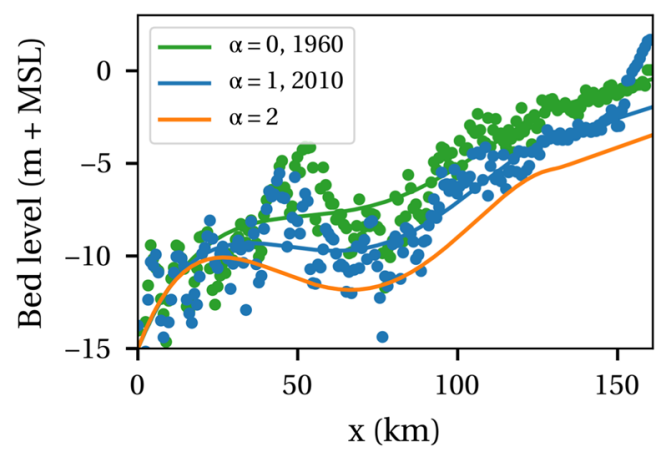

Fig. 11 Width-averaged bed level (m + MSL) observed in 1960 and 2010 (dots) and smooth fits, together with smooth bed profiles for a deepening scenario with $\alpha=2$ (see Eq. 6) by extrapolating the pattern of deepening between 1960 and 2010. We vary $\alpha$ between 0 and 2, keeping all other parameters the same as in the default experiment (Table 2).

Model results show that channel deepening between 1960 and 2010 leads to an amplification of the $M_{2}$ water level, thereby confirming observations from measurements and earlier model studies (Winterwerp et al. 2013; Cai and Savenije 2013). Furthermore, we find a combination of amplification and damping of the $M_{4}$ water level with deepening. Figure 12a shows the $M_{2}$ and $M_{4}$ water level amplitude for $\alpha=0,1$ and 2, together with observations of the tidal amplitude in 1960 and 2009. In order to compare the model result and measurements for 1960, the modelled water level for $\alpha=0$ is for a situation without sediment dumping, while dumping is taken into account for $\alpha>0$. Although the modelled $M_{2}$ tide is only calibrated for 2010 conditions, the $M_{2}$ tide for $\alpha=0$ shows good correspondence with the 1960 observations. As $\alpha$ increases, the $M_{2}$ tidal amplitude increases for all tested values of $\alpha$. The $M_{4}$ tidal amplitude is overestimated compared to the measurements in both 1960 and 2010 conditions. Between 1960 and 2010, the measurements show only very minor changes in $M_{4}$ tidal amplitude, with amplification upstream from $\mathrm{km} 130$ and reduction of the amplitude downstream from $\mathrm{km} \mathrm{130.} \mathrm{For} \alpha$ increasing from 1 to 2, the model does capture a trend similar to what was observed between 1960 and 2010, with increasing $M_{4}$ amplitude upstream from $\mathrm{km}$ 140 and decreasing amplitude elsewhere.

The maximum sediment concentrations become lower as a result of channel deepening. This is illustrated in Fig. 12b, which shows the depth-averaged sediment concentration as a function of $x$ and the bed-profile parameter $\alpha$ for year-averaged discharge. Sediment dumping is now taken into account and has its default value for all $\alpha$. For $\alpha=$ 0 , the figure shows two ETM around $\mathrm{km} 80$ and 115 . As $\alpha$ increases (moving up along the vertical axis), the sediment concentrations in the ETM become lower. From approximately $\alpha>0.9$, the ETM at $\mathrm{km} 115$ starts to disappear and is replaced by an ETM at $\mathrm{km} \mathrm{150.} \mathrm{As} \alpha$ increases further, the concentrations in this new ETM at $\mathrm{km} 150$ also decrease. Repeating these model experiments without sediment dumping (not shown) yields similar results; however, the ETM at km 80 is much weaker. Hence, regardless of sediment dumping, the effect of deepening alone leads to an upstream shift of the ETM from $\mathrm{km} 115$ to $\mathrm{km} 150$ and lower maximum sediment concentrations.

\subsection{Sensitivity to the settling velocity and erosion parameter}

The effect of channel deepening for other values of the settling velocity $w_{s, 0}$ and erosion parameter $M$ is generally consistent i.e. showing decreasing concentrations with 


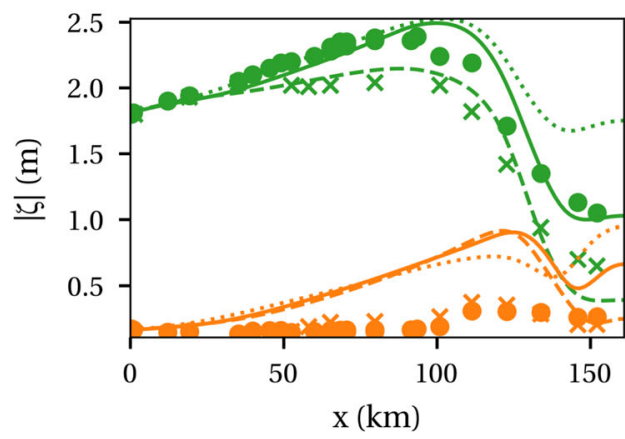

(a) Water level amplitude

Fig. 12 a Water level amplitude of the $M_{2}$ (green) and $M_{4}$ (red) tide for $\alpha=0$ (1960), $\alpha=1$ (2010) and $\alpha=2$ (dashed, solid, dotted, respectively), compared to observations from 1960 (crosses) and 2009 (dots). Results are for the average discharge case $\left(Q=110 \mathrm{~m}^{3} / \mathrm{s}\right)$ with dumping for $\alpha=1,2$ and without dumping for $\alpha=0$ in order to

deepening. However, this is not true for all combinations of $w_{s, 0}$ and $M$, see Fig. 13. The figure shows the relative change of the maximum depth-averaged concentration for $\alpha=2$ compared to $\alpha=1$ (2010) for the ETM seaward and landward of $\mathrm{km} 125$ for average and summer

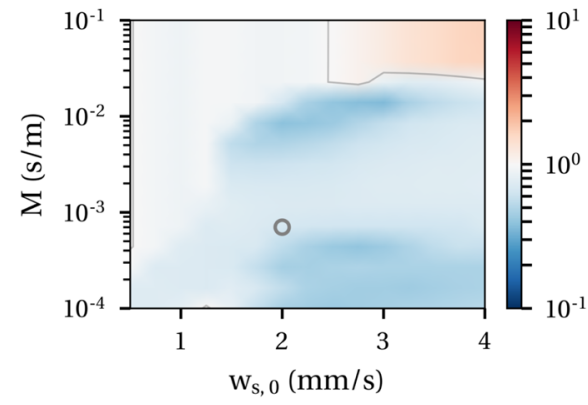

(a) Average conditions $\left(Q=110 \mathrm{~m}^{3} / \mathrm{s}\right)$ seaward of $\mathrm{km}$ 125 .

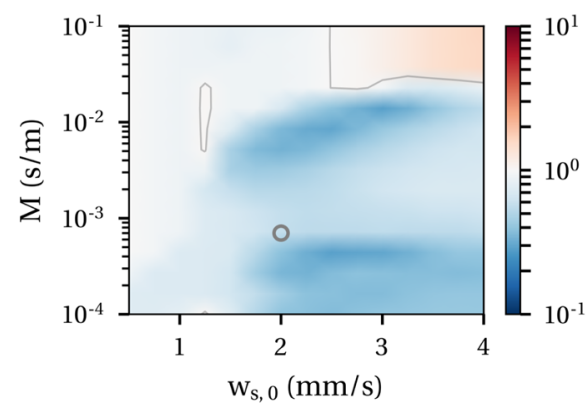

(c) Summer conditions $\left(Q=56 \mathrm{~m}^{3} / \mathrm{s}\right)$ seaward of $\mathrm{km}$ 125.

Fig. 13 Ratio of the maximum depth-averaged concentration for $\alpha=$ 2 (deepened) divided by that for $\alpha=1$ (2010) in the areas seaward and landward of $\mathrm{km} 125$ for average and summer discharge conditions, plotted for a range of values of $w_{s, 0}$ and $M$. Blue colours denote that

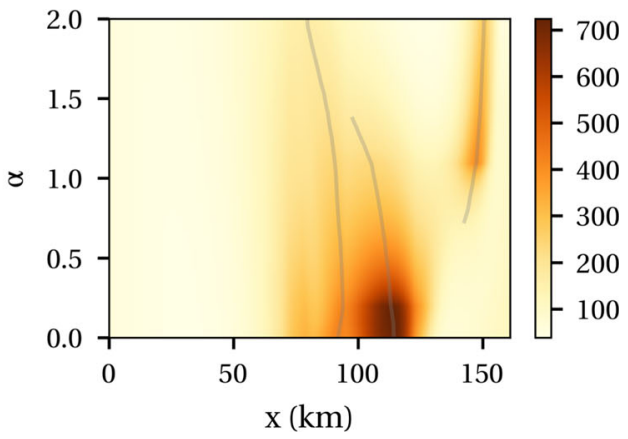

(b) Subtidal depth-averaged sediment concentration (in $\mathrm{mg} / \mathrm{l}$ ).

compare with 1960 observations. b Subtidal depth-averaged sediment concentration as a function of $x$ and bed-profile parameter $\alpha$, where increasing $\alpha$ indicates increasing channel depth. Results are for the average discharge case $\left(Q=110 \mathrm{~m}^{3} / \mathrm{s}\right)$ with dumping included for all $\alpha$. The grey contour lines indicate the location of the ETM

discharge cases. Red colours indicate an increase of the maximum concentration after deepening, while blue colours indicate a decrease. For both average $\left(Q=110 \mathrm{~m}^{3} / \mathrm{s}\right.$, Fig. 13a-b) and summer $\left(Q=56 \mathrm{~m}^{3} / \mathrm{s}\right.$, Fig. 13c-d) discharges, the concentrations predominantly decrease.

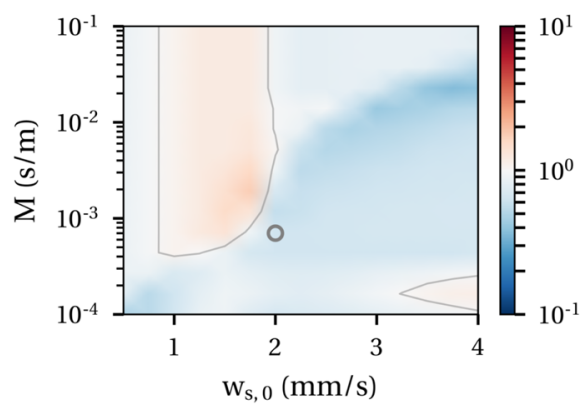

(b) Average conditions $\left(Q=110 \mathrm{~m}^{3} / \mathrm{s}\right)$ landward of $\mathrm{km}$ 125 .

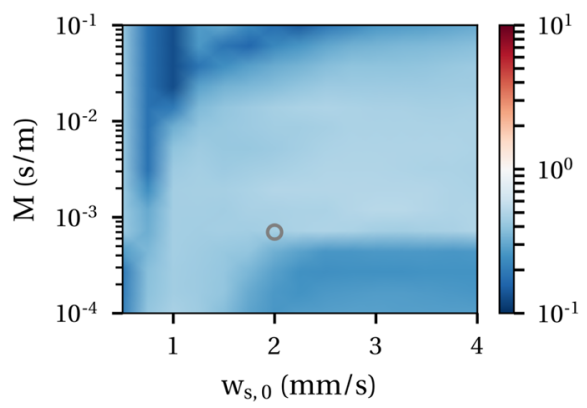

(d) Summer conditions $\left(Q=56 \mathrm{~m}^{3} / \mathrm{s}\right)$ landward of $\mathrm{km}$ 125 .

the maximum concentration is lower for $\alpha=2$ than for $\alpha=1$. Red colours denote that the maximum concentration is higher for $\alpha=2$ than for $\alpha=1$. The contour line indicates no change between the scenarios. The circles indicate the default parameter settings (Table 2) 
Increasing concentrations with deepening are found for a combination of a high erosion parameter and high settling velocity in the ETM seaward of $\mathrm{km} 125$. For these settings, the estuary is already highly turbid for 2010 depth conditions (see Section 3.3), so the increasing concentration with deepening does not signify a transition from low to high sediment concentrations. In the ETM landward of

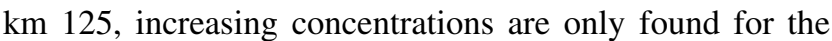
year-averaged discharge case for settling velocities between approximately 1 and $2 \mathrm{~mm} / \mathrm{s}$ and $M>10^{-3} \mathrm{~s} / \mathrm{m}$. The increase is, however, less than a factor two and also does not indicate a transition from low to high sediment concentrations.

\section{Analysis}

In order to gain a better understanding of and confidence in the presented results, we investigate the physical processes underlying the sediment dynamics in the model. Following the approach taken by Dijkstra et al. (2019), the model results before and after deepening are analysed on the basis of two aspects:

1. along-channel suspended sediment transport; and

2. vertical resuspension

These aspects are quantitatively expressed in terms of the transport capacity, erodibility and dimensionless erosion parameter, which are introduced in Section 5.1. Next, in Section 5.2, we analyse the sediment dynamics in the 2010 case. This is used to explain the sensitivity to the erosion parameter in Section 5.3 and to deepening in Section 5.4.

\subsection{Transport capacity, erodibility and dimensionless erosion parameter}

In order to analyse the vertical resuspension of sediment, we look closer at the formulation for erosion $E$ in iFlow, which reads as

$E=M\left|\tau_{b}\right| f$.

Here, $M$ is a prescribed erosion parameter, $\tau_{b}$ is the bed shear stress and $f$ is the tidally averaged erodibility. This erodibility indicates the tidally averaged amount of sediment on the bed. The erodibility is a number between 0 and 1 , where 0 means that no sediment is available for erosion during the entire tidal cycle and 1 indicates that easily erodible sediment is available at the bed during the entire tidal cycle. A number between 0 and 1 indicates that sediment is available at the bed during some part of the tide. A formal mathematical definition is provided by Brouwer et al. (2018).
Using this erosion formulation, one can define a dimensionless erosion parameter $\tilde{E}$ (see Dijkstra et al. (2018)), which expresses the ability of the flow to resuspend sediment from the bed. For our model, it is mathematically expressed as

$\tilde{E}=\frac{M\left|\tau_{b}\right|}{w_{s, 0} c_{\text {gel }}}$,

where the clear-water settling velocity $w_{s, 0}$ and gelling concentration $c_{\text {gel }}$ are constants in our model. Hence, the along-channel variation of $\tilde{E}$ expresses along-channel variations in the bed shear stress $\tau_{b}$.

In order to analyse changes in sediment dynamics, one could directly investigate the changes in the sediment transport. The disadvantage of this is that the sediment transport is typically large near the ETM and small in areas with little sediment. Hence, when the ETM moves to a location where little sediment was available previously, this appears as a large change in the sediment transport. The changes in the sediment transport then simply reflect the changes in ETM location, not the changes in hydrodynamic forcing that caused the ETM to move. To circumvent this, we use the concept of transport capacity. A formal mathematical definition of the transport capacity is provided in by Chernetsky et al. (2010) or Dijkstra et al. (2019). More intuitively, the transport capacity is defined as the sediment transport that would occur if a uniform layer of sediment was added on the bed everywhere in the estuary, given the modelled hydrodynamic conditions (flow velocity, turbulence field) and sediment parameters (effective settling velocity, erosion parameter). It therefore indicates the tidally averaged redistribution of a uniform layer of sediment on the bed. Trapping of sediment, here defined as a local maximum of the erodibility, is indicated by a convergence of the transport capacity.

In iFlow, the transport capacity can be subdivided into various physical contributions. The most dominant contributions in the Scheldt River are the following.

- The external $M_{4}$ tide contribution is due to tidal asymmetry caused by the $M_{2}$ tide and $M_{4}$ tide entering the estuary at the mouth. The contribution to the $M_{4}$ tide is generated outside the estuary on the shallow shelf and propagates through the estuary, causing asymmetry in the velocity and sediment resuspension during ebb and flood and therefore net sediment transport.

- The tidal return flow contribution is the transport capacity due to Stokes drift and the corresponding return flow. The Stokes drift is associated with sediment import. At least partly compensating this import, the return flow velocity contains a subtidal contribution which typically causes export of sediment. Additionally, the return flow velocity has an $M_{4}$ 
contribution, which may cause import or export of sediment, depending on the phase lag with the $M_{2}$ tide.

- The velocity-depth asymmetry contribution is the transport capacity due to the asymmetry of the tide that is created because the depth is different during ebb and flood. This yields different velocity profiles during ebb and flood and hence asymmetric sediment resuspension and transport. Whether this effect is importing or exporting sediment depends on the phase difference between the $M_{2}$ velocity and surface elevation.

- The sediment advection contribution represents the transport due to spatial settling lag (see e.g. Van Straaten and Kuenen 1957, De Swart and Zimmerman 2009). This contribution tends to transport sediment towards along-channel minima in the tidal velocity amplitude.

- The river contribution consists of two parts: the riverinduced flushing of tidally resuspended sediment and the transport due to the tidal asymmetry caused by the tide-river interaction. Both contributions cause an export of sediment

The above contributions to the sediment transport capacity contain correlations of subtidal velocities and sediment concentrations, as well as correlations of tidally varying velocities and sediment concentrations, known as tidal pumping (see e.g. Burchard et al. (2018) for a review). Tidal pumping can be further related to $M_{2}-M_{4}$ tidal asymmetry, which is contained in the above contributions by the external $M_{4}$ tide, tidal return flow and velocity-depth asymmetry. Other contributions to tidal pumping are related to the asymmetry caused by the subtidal flow, contained in the river contribution, tidal return flow and velocitydepth asymmetry, and to spatial gradients, contained in the sediment advection contribution.

\subsection{Analysis of the 2010 case}

Analysis of the sediment transport capacity provides more insight into the ETM near $\mathrm{km} 80$ and 150. Figure 14a shows the transport capacity for the 2010 case with average discharge $\left(Q=110 \mathrm{~m}^{3} / \mathrm{s}\right)$ with sediment dumping and is almost the same for the case without dumping. The total transport capacity (black line) shows the ability of the flow to transport sediment upstream (positive) or downstream (negative). Sharp jumps occur in the transport capacity at $\mathrm{km} 95$ and 123, due to the inflow of fresh water from tributaries. The ETM correspond to the two convergence zones near $\mathrm{km} 80$ and 150, indicated by the numbers in

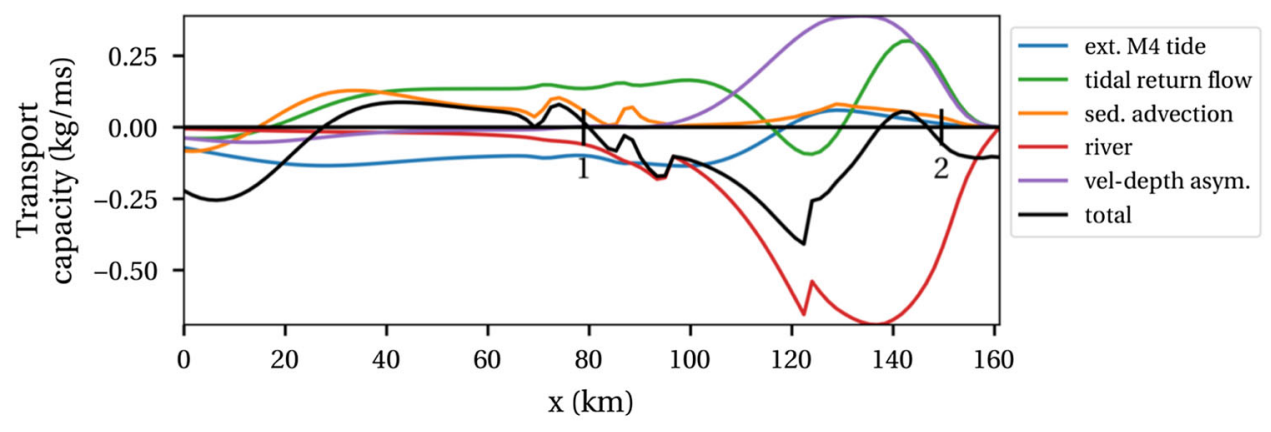

(a) Total transport capacity and decomposition of the transport capacity into its five most important contributions. The vertical markings and numbers denote trapping locations.

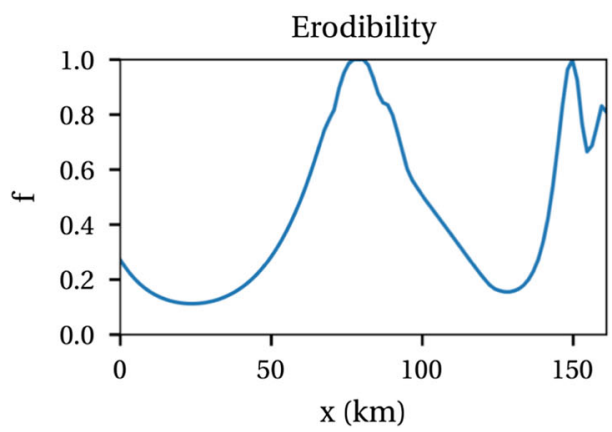

(b) Erodibility.

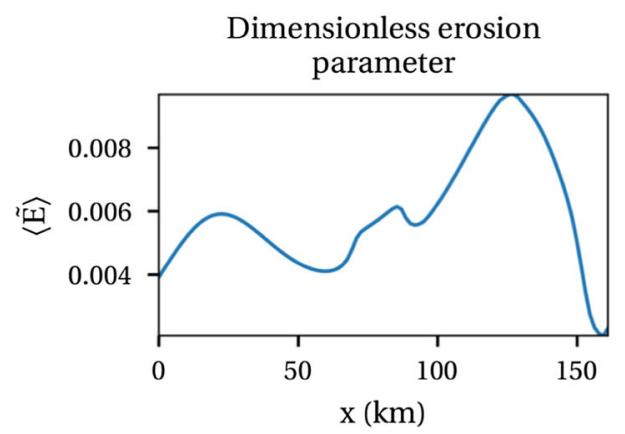

(c) Dimensionless erosion parameter.

Fig. 14 Quantities used for the analysis of sediment transport and resuspension: the transport capacity, erodibility and dimensionless erosion parameter. These quantities are plotted for the case with average discharge $\left(Q=110 \mathrm{~m}^{3} / \mathrm{s}\right)$ with dumping 
the figure. The convergence near $\mathrm{km} 80$ is a result of a clear upstream transport between $\mathrm{km} 25$ and 80 and a clear downstream transport between $\mathrm{km} 80$ and 140. The convergence near $\mathrm{km} 150$ on the other hand results from only a small area of weak upstream transport near km 140 and downstream transport from the landward boundary. This trapping zone and the corresponding ETM could therefore potentially disappear if small changes were made to the parametrisation of the geometry near the landward end of the model domain. Hence, there is significant uncertainty about this ETM in the model. The measurements provide an ambiguous image of this ETM as well; the ETM at km 150 is not observed in the OMES observations, while its is observed by the continuous measurement station near Melle. Further research is needed to provide further understanding of the sediment concentration in this part of the estuary.

The reason why convergence of transport occurs, follows from the balance of dominant physical mechanisms, which are also shown in Fig. 14a. There are two dominant exporting (i.e. negative) contributions. The river discharge dominates the sediment export from the estuary for $x>80$ $\mathrm{km}$. For $x<80 \mathrm{~km}$, sediment export is dominated by the sediment transport due to $M_{2}-M_{4}$ tidal asymmetry that is related to the externally forced $M_{4}$ tide. Three contributions are important for import (i.e. positive): sediment advection (or spatial settling lag), tidal return flow and velocitydepth asymmetry. The latter two are associated with $M_{2}-$ $M_{4}$ asymmetry of the tide. Hence, sediment transport due to $M_{2}-M_{4}$ tidal asymmetry is important, but not all contributions to this asymmetry lead to sediment import. The resulting combined transport by the $M_{2}-M_{4}$ asymmetry is a small import of sediment for $x>40 \mathrm{~km}$.

While the sediment transport capacity shows that the observed ETM near $\mathrm{km} 80$ and 150 are results of sediment trapping, it cannot explain the ETM observed at the surface near km 115 (see Fig. 7b). This ETM is not directly related to a trapping zone but results from a large resuspension of sediment. This results from the combination of a sufficiently large availability of sediment, expressed by the erodibility (Fig. 14b) and a relatively large erosion, expressed by the tidally averaged dimensionless erosion parameter (Fig. 14c). The sediment available at the bed is suspended high up in the water column and is therefore observed as an ETM at the surface.

\subsection{Analysis of the sensitivity to the erosion parameter}

The erodibility helps to explain why the model results are sensitive to the erosion parameter, as was found in Fig. 9. Near the ETM at km 80 and 150, the erodibility (Fig. 14b) equals one. This means that sediment is always available on the bed at these locations. The maximum sediment concentration in these ETM is limited by the ability of the flow to resuspend sediment (i.e. erosion limited conditions). Hence, the sediment concentration at these locations increases when the erosion parameter is increased. Results indicate that erosion limited conditions prevail for average discharge conditions at these ETM locations for $M$ up to $10^{-2} \mathrm{~s} / \mathrm{m}$ if the settling velocity exceeds $2 \mathrm{~mm} / \mathrm{s}$ (not shown). This is over 10 times the erosion parameter used in this study. If dumping were not included in the model, less sediment would be available at the bed but erosion limited conditions still prevail for $M$ up to $10^{-3} \mathrm{~s} / \mathrm{m}$ (for a settling velocity of $2 \mathrm{~mm} / \mathrm{s}$ ) to $10^{-2}$ $\mathrm{s} / \mathrm{m}$ (for a settling velocity of $4 \mathrm{~mm} / \mathrm{s}$ ). Therefore, regardless of dumping, the development of hyperturbid conditions in the Scheldt, within our model, is mainly controlled by the exchange of sediment between the water column and the bed, parametrised by the erosion parameter.

\subsection{Analysis of the response to deepening}

To analyse why deepening leads to lower sediment concentrations, the above analysis is repeated for the case $\alpha=2$ (i.e. deepening), and results are compared to the case $\alpha=1$ (i.e. 2010). The total sediment transport capacity (Fig. 15a) shows only minor changes due to deepening in the seaward half of the estuary. In addition, the locations of the trapping zones near $\mathrm{km} 80$ and 150 (indicated by the numbers) change only little, moving slightly further apart. Only between the two trapping locations does the transport capacity change, leading to an increasing convergence of sediment near the trapping locations. Corresponding to this, the transport capacity diverges between the trapping zones, and less sediment is found between $\mathrm{km} 80$ and 150 .

The relatively minor changes in the transport capacity are caused by a mixed response of the underlying mechanisms to deepening (not shown). The sediment transport related to the external $M_{4}$ tide becomes more exporting. Additionally, the sediment transport related to tidal return flow becomes less importing between $\mathrm{km} 0$ and 80 . The transport due to other mechanisms does not change much between $\mathrm{km} 0$ and 80. Between the ETM at $\mathrm{km} 80$ and 150, the increasing divergence is found in the tidal return flow, as well as the velocity-depth asymmetry and spatial settling lag.

As the trapping locations do not change much due to deepening, the explanation for the lower maximum concentration follows from the erodibility and dimensionless

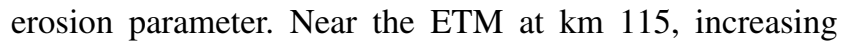
divergence of sediment transport capacity means that less sediment is available, which is expressed by a lower erodibility, see Fig. 15b. As a result, the sediment concentration in this ETM decreases with deepening. In the ETM near $\mathrm{km} 80$ and 150, the erodibility remains equal to one, since the sediment transport still strongly converges in these 


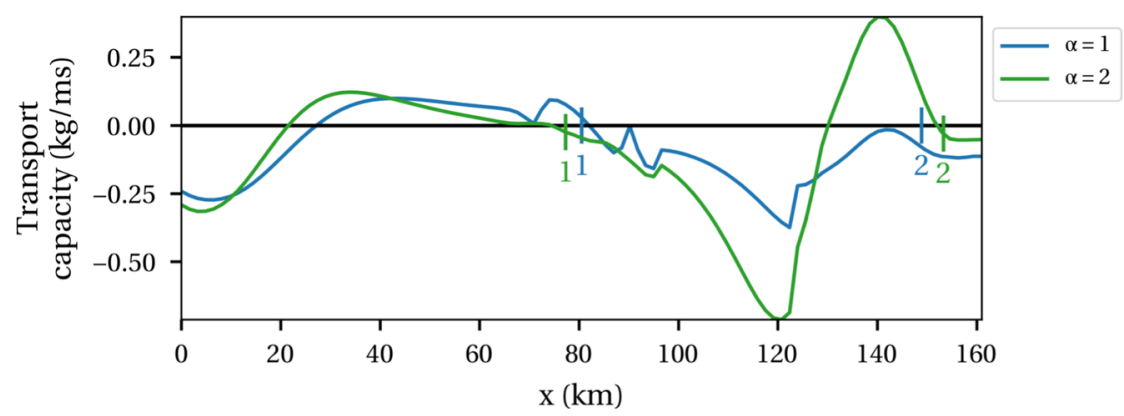

(a) Total transport capacity for the 2010 case $(\alpha=1)$ and the case for $\alpha=2$.

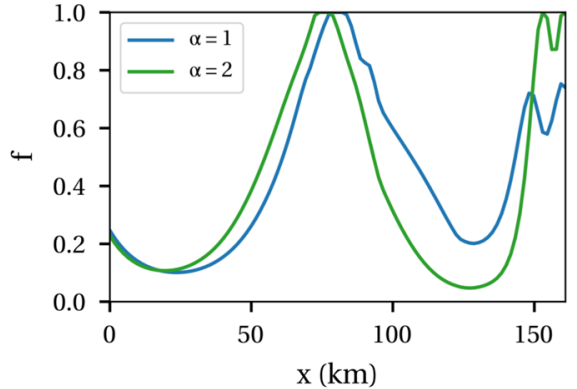

(b) Erodibility.

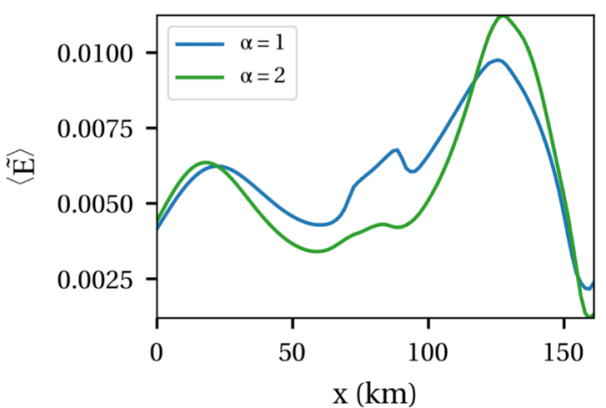

(c) Dimensionless erosion parameter.

Fig. 15 Transport capacity, erodibility and dimensionless erosion parameter for the cases $\alpha=1$ (2010) and $\alpha=2$ for average discharge $(Q=110$ $\mathrm{m}^{3} / \mathrm{s}$ ) with dumping

areas. Therefore, the maximum concentration in these ETM is restricted by the dimensionless erosion parameter. The dimensionless erosion parameter (Fig. 15c) decreases after deepening near $\mathrm{km} 80$. This is related to a decrease in the bed shear stress, which is caused by a decrease in the $M_{2}$ tidal velocity in response to deepening. This explains why the sediment concentration becomes lower near $\mathrm{km}$ 80 after deepening. Near km 150, the trapping zone moves slightly upstream (see above), where the dimensionless erosion parameter is smaller. This explains the lower sediment concentrations in this ETM.

\section{Discussion}

\subsection{Comparison with the Ems River Estuary}

The main motivation to study whether hyperturbid conditions can develop in the Scheldt as a consequence of deepening is the development of hyperturbid conditions as a consequence of deepening in the Ems. However, we found that the effects of deepening in the Ems and Scheldt are different. These differences are explained below.

Using the same iFlow model as in this study, the observed transition to hyperturbid conditions in the Ems was qualitatively reproduced by Dijkstra et al. (2019). This was done by calibrating the model to a situation representing 1965 (before hyperturbid conditions developed) and then changing the depth to conditions representing 2005 (after hyperturbid conditions developed). It was concluded that the sediment dynamics in the Ems is supply limited i.e. the erodibility is smaller than 1, and sediment concentrations are restricted by the ability of the estuary to import sediment. It was found that the most important physical mechanisms responsible for import in the Ems are the $M_{2}-M_{4}$ tidal asymmetries related to the externally generated $M_{4}$ tide and tidal return flow. With deepening, both mechanisms become more importing. The additional import of sediment leads to sediment-induced stratification, which leads to damping of turbulence. This in turn leads to a further increase of sediment import due to the $M_{2}-M_{4}$ tidal asymmetry.

The sediment dynamics in the Scheldt behaves differently to the Ems in two aspects. Firstly, it is concluded in this study that the most intense ETM locations in the Scheldt are erosion limited. Hence, the maximum sediment concentration is not restricted by the ability of the estuary to import sediment but by the ability to resuspend sediment from the bed. With deepening, it is found that the bed shear stress decreases in the Scheldt in the ETM near km 80, explaining the lower sediment concentrations. A decrease in the bed shear stress with deepening is also found locally in the Ems but does not restrict the sediment concentration there. 
Secondly, deepening does not lead to an increasing import by all sediment transport mechanisms. On the contrary, the transport related to the externally generated $M_{4}$ tide becomes more exporting, while transport related to the internally generated $M_{4}$ tide become less importing in a large part of the estuary. As deepening does not lead to an increasing sediment concentration, a feedback between sedimentinduced damping of turbulence and sediment import, as in the Ems, cannot develop in the Scheldt.

The underlying reasons why deepening lead to increasing sediment import in the Ems but not in in the Scheldt follow from a complex interplay between the non-linear generation of the $M_{4}$ tide and the phase difference between the $M_{2}$ and $M_{4}$ tide. Nevertheless, one of these reasons can be understood intuitively. At the mouth of the estuary (taking the mouth of the Ems River at Knock), the phase difference between the $M_{2}$ and $M_{4}$ tide is -4 degrees in the Scheldt and -172 degrees in the Ems. This is a difference of almost 180 degrees, explaining why the effects of the externally generated $M_{4}$ tide on transport are almost completely opposite in the Scheldt and the Ems. Deepening leads to amplification of the externally generated $M_{4}$ tide inside the estuary in both the Scheldt and Ems and hence to more export in the Scheldt and more import in the Ems.

\subsection{Effect of model simplifications}

As this model study is highly idealised, there are many physical processes that are not included and some processes that are not represented accurately. Nevertheless, as we have studied the sensitivity of the model to parameter variations and have investigated the most essential physical mechanisms in the model, it is possible to discuss the robustness of the results with respect to these model simplifications.

One of the main discrepancies between the model results and observations is the amplitude of the $M_{4}$ water level and the velocity (e.g. Fig. 6), which are overestimated by more than a factor 2 in the upstream part of the estuary. The reason for this overestimation is unknown and could potentially be related to an oversimplification of the geometry, such a neglecting tidal variations in estuary width (see e.g. Friedrichs and Aubrey 1994), or oversimplification of bed friction and eddy viscosity as a time-independent quantities, such that interactions of tidal constituents to create tidal damping is not fully included (see e.g. Godin 1999).

The effect of the overestimation of the $M_{4}$ tide has been tested in our model by artificially scaling to match the observations. Results show only slight variations in sediment concentration and the sensitivity studies of $M$ and $w_{s}$, such that the primary conclusions are not affected. This ad-hoc sensitivity test suggests that the mismatch between measured and modelled $M_{4}$ tide does not appreciably alter results. This relative unimportance of the error in the $M_{4}$ tide is because of several reasons. Firstly, since the estuary is erosion limited, the spatial variation of the $M_{2}$ tide (and modelling that correctly) is most important. Secondly, the phase difference between the $M M_{2}$ and $M_{4}$ tide determines the direction of the net transport, and this phase difference is captured correctly by the model. Finally, our conclusions consider the relative change of the concentration as a consequence of the relative change in dynamics after deepening. Hence, the absolute values of the $M_{4}$ tidal amplitude are less important as long as relative changes are captured. Hence, our conclusions seem robust to the errors in the modelled $M_{4}$ tide, but further study is strongly recommended to verify what contributions to the $M_{4}$ tide are missing in this model.

A process that is often considered to be important in the Scheldt is flocculation (e.g. Chen et al. 2005). Flocculation affects the settling velocity of sediment. In this study, we have shown that the results are robust for large changes in the settling velocity in the entire estuary. Hence, large-scale changes in the settling velocity due to changing flocculation properties do not affect our conclusions. The remaining uncertainty is related to spatial or temporal variations of the settling velocity, which are not taken into account.

As erosion is the most restricting process to the sediment concentration, and as it is found that higher sediment concentrations may occur in the Scheldt for larger values of the erosion parameter, the erosion formulation requires most direct attention of further research. The erosion formulation used in this study is based on Partheniades' formulation, which is also used in many state-of-the-art complex models. In this study, we have simplified this formulation by ignoring the critical shear stress and omitting tidal variations of the sediment availability at the bed. While these simplifications likely have important consequences for the quantitative results, they do not change the qualitative conclusions. The main source of uncertainty is the erosion parameter. It remains unknown whether the value of this parameter changes on the long timescale or as a response to deepening. It was identified in this study that hyperturbid conditions can occur in the Scheldt if the value of the erosion parameter is increased by one to two orders of magnitude. Further research is needed to investigate if this is possible.

Our conclusion is further supported by studies using complex models of the Scheldt. Using a depth-averaged Delft3D model, Van Kessel et al. (2008) investigated the effect of the second deepening campaign (1997-1998) and found that this deepening should lead to lower suspended sediment concentrations. Using a three-dimensional model, Vandenbruwaene and Stark (2018) show that the tide in the estuary became less flood dominant due to deepening since the 1930s, also suggesting less sediment import due to deepening. 


\section{Conclusion}

We have investigated the hypothesis of Winterwerp and Wang (2013) that the Scheldt may become hyperturbid as a response to deepening. To this end, we have used the iFlow model to investigate the dynamic equilibrium sediment concentration in the Scheldt for a case representing conditions of 2010 and a range of cases with higher and lower bed levels, keeping all other parameters the same. In order to draw robust conclusions, all cases have been tested for a range of values of uncertain parameters and the physics underlying the sediment dynamics has been investigated.

For the conditions representing 2010, the modelled sediment concentrations qualitatively reproduce observed longterm average ETM locations and sediment concentration magnitudes. From the analysis, it is found that the most intense ETM locations in the Scheldt are erosion limited i.e. the maximum sediment concentration is restricted by the ability of the flow to resuspend sediment from the bed, not by the availability of sediment. Hence, model results are sensitive to the quantities that control the amount of resuspension, which are mainly the bed shear stress and an erosion parameter.

Deepening of the estuary in the model generally leads to lower maximum sediment concentrations in the Scheldt. When investigating the sensitivity to varying parameter values, some parameter settings were identified where the maximum concentration increases with deepening but such increase is minor and does not lead to the development of hyperturbid conditions. The analysis shows that the flow velocity and hence the bed shear stress at the ETM locations generally decrease with deepening. This results in a reduction of resuspension, which in turn results in lower sediment concentrations. Furthermore, deepening does not lead to a clear trend of increasing sediment import in the Scheldt. Overall, deepening leads to less import in the most seaward part of the estuary and more convergence of sediment around the ETM.

Based on these results, we suggest to reject the hypothesis of Winterwerp and Wang (2013) that channel deepening alone may lead to development of hyperturbid conditions in the Scheldt. By combining the model results, sensitivity analysis and understanding of underlying processes, we argued that this is a robust conclusion, even though the model used is highly idealised. To further verify this conclusion, it is recommended to investigate some processes that are missing or inaccurately represented by the model. Firstly, this concerns the $M_{4}$ tide, which is overestimated in the model. Secondly, this concerns the parametrisation for erosion. High sediment concentrations were found in the model of the Scheldt when the erosion parameter is increased by one or two orders of magnitude compared to its calibrated value and it remains unknown whether such an increase of the erosion parameter could occur.

Acknowledgements We sincerely thank Yves Plancke (Flanders Hydraulics Research) and Wouter Vandenbruwaene (Flanders Hydraulics Research, HIC) for providing insight into available data and studies on the Scheldt. We thank Rijkswaterstaat for providing data on water levels, velocities, salinities and sediment concentrations in the Western Scheldt. We thank HIC for providing the water level observations and data from the continuous sediment concentration measurement stations in the Sea Scheldt and Flanders Hydraulics Research (MONEOS programme) for the velocity measurements. We further thank the Flemish Waterway for permission to use the OMES dataset, and we thank Thijs van Kessel (Deltares) for sharing earlier studies done in context of the LTV project on mud modelling. Finally, we thank Carl Friedrichs, Stefan Talke and an anonymous reviewer for their reviews of this work.

Open Access This article is distributed under the terms of the Creative Commons Attribution 4.0 International License (http:// creativecommons.org/licenses/by/4.0/), which permits unrestricted use, distribution, and reproduction in any medium, provided you give appropriate credit to the original author(s) and the source, provide a link to the Creative Commons license, and indicate if changes were made.

\section{Appendix A: Turbulence-bed friction model}

Turbulence in the model is parametrised using an eddy viscosity $A_{v}$ and eddy diffusivity $K_{\nu}$, which are specified according to

$A_{v}=\left\langle c_{v, 1}\left(z_{0}^{*}\right) U(H+R+\zeta) F(\overline{R i})\right\rangle$,
$K_{v}=\left\langle c_{v, 2}\left(z_{0}^{*}\right) U(H+R+\zeta) G(\overline{R i})\right\rangle$,

where $c_{v, 1}\left(z_{0}^{*}\right), c_{v, 2}\left(z_{0}^{*}\right)$ are prescribed functions of the dimensionless roughness height $z_{0}^{*}$ (see Dijkstra et al. (2017)), $U$ is the depth-averaged velocity and $F$ and $G$ are the Munk and Anderson (1948) damping functions of the depth-averaged gradient Richardson number $\overline{R i}$. The gradient Richardson number is defined as

$R i=-\frac{g \beta_{c}}{\rho_{0}} \frac{c_{z}}{u_{z}^{2}+u_{z, \min }^{2}}$,

where $g$ is the acceleration of gravity, $\beta_{c}$ is the conversion factor from sediment concentration to density, $\rho_{0}$ is the reference density of water and $u_{z}$ and $c_{z}$ are the vertical gradients of the velocity and sediment concentration. The parameter $u_{z, \min }$ is a background shear that parametrises turbulence production by unresolved flows (e.g. lateral flow, wind-driven flow, small-scale circulation), nonlocal turbulence production and inertia in turbulence dissipation and thereby prevents the Richardson number from becoming unrealistically large. 
At the bed, we impose a non-linear friction law for the water motion by imposing that the bed shear stress equals $\rho_{0} s_{f} u_{\text {bed }}$, where $u_{\text {bed }}$ is the along-channel velocity near the bed and $s_{f}$ is the partial slip parameter that depends on the depth-averaged velocity $U$ as

$s_{f}=\left\langle c_{v, 3}\left(z_{0}^{*}\right) c_{D} U \frac{H}{H_{x=0}}\right\rangle$.

Here, $c_{v, 3}\left(z_{0}^{*}\right)$ is a prescribed function of $z_{0}^{*}$ and $c_{D}$ is a reduced drag function that depends on the sediment stratification near the bed according to Adams and Weatherly (1981), Friedrichs et al. (2000), and Wang (2002)

$c_{D}=\left(1+A\left\langle R f_{\text {bed }}\right\rangle\right)^{-2}$,

where $A=5.5$ is an empirical parameter and $R f_{\text {bed }}$ is the flux Richardson number near the bed. We restrict $R f_{\text {bed }}$ to a maximum value of 2 to ensure that the friction does not become much smaller than observed in laboratory studies. For sediment erosion and resuspension, the bed-shear stress $\tau_{b}$ in Eq. 1 is parametrised as

$\tau_{b}=\rho_{0} s_{s} u_{\text {bed }}$,

where the parameter $s_{s}$ equals $s_{f}$ (12) but assuming $c_{D}=1$. Sediment erosion is therefore not affected by reduced drag due to near-bed stratification.

\section{Appendix B: New model additions related to tributaries}

The discharge of water into the estuary by tributaries is added to the model as depth-integrated point sources by adding source terms to the depth-averaged continuity equation, i.e.

$B \zeta_{t}+\left(B \int_{-H}^{R+\zeta} u\right)_{x}=\sum_{n} S_{Q, n} \delta\left(x-x_{n}\right)$

where $B$ is the width, $H$ is the depth below mean sea level (MSL) $z=0, R$ is the reference level above MSL, $\zeta$ is the surface elevation, $u$ is the horizontal flow velocity and subscripts $x$ and $t$ indicate derivatives with respect to alongchannel distance and time, respectively. The source terms $S_{Q, n}$ represent the discharge of tributary $\mathrm{n}$ at location $x_{n}, \delta$ denotes the Dirac delta function i.e. indicating a source at one point. These sources lead to an additional contribution to the first-order residual water motion (see Dijkstra et al. 2017) that can be analysed separately.

Sources of sediment enter into the sediment concentration is computed using an equation for mass conservation and an equilibrium condition, which requires that the crosssectionally integrated sediment concentration does not vary on the subtidal timescale. This condition is equivalent to requiring

$$
\left\langle B \int_{-H}^{R+\zeta}\left(u c-K_{h} c_{x}\right) d z\right\rangle_{x}=B(E-D)+S .
$$

In this equation, $\langle\cdot\rangle$ denotes tidal averaging, $c$ is the sediment concentration, $K_{h}$ is the horizontal eddy diffusivity, $E$ denotes erosion or resuspension from the bed and $D$ denotes deposition. Fluvial sources of sediment, dreding and dumping are added to the model by adding a source or sink of sediment $S$, which consists of pulses that equal the rate of sediment added (positive) or extracted (negative) from the system at the confluences, dredging and dumping locations. The model computes itself how the sources and sinks are distributed over the water column and the bed in such a way that the model remains in dynamic equilibrium.

\section{References}

Adams CE, Weatherly GL (1981) Some effects of suspended sediment stratification on an oceanic bottom boundary layer. J Geophys Res: Oceans 86:4161-4172. https://doi.org/10.1029/jc086ic05p04161

Barneveld HJ, Nicolai RP, Boudewijn TJ, Van De Moortel I, Postma R (2018) Evaluatie Schelde-estuarium: de toestand van Veiligheid, Toegankelijkheid en Natuurlijkheid. Samenvatting van de T2015rapportage. Tech. Rep. PR3152.10, HKV, Bureau Waardenburg and Antea, in Dutch

Brouwer RL, Schramkowski GP, Dijkstra YM, Schuttelaars HM (2018) Time evolution of estuarine turbidity maxima in wellmixed, tidally dominated estuaries: the role of availabilityand erosion-limited conditions. J Phys Oceanogr 48:1629-1650. https://doi.org/10.1175/jpo-d-17-0183.1

Burchard H, Schuttelaars HM, Ralston DK (2018) Sediment trapping in estuaries. Ann Rev Mar Sci 10:14.1-14.25. https://doi.org/10.1146/annurev-marine-010816-060535

Cai H, Savenije HHG (2013) Asymptotic behavior of tidal damping in alluvial estuaries. J Geophys Res: Oceans 118:6107-6122. https://doi.org/10.1002/2013jc008772

Chen MS, Wartel S, Eck BV, Maldegem DV (2005) Suspended matter in the Scheldt estuary. Hydrobiologia 540:79-104. https://doi.org/10.1007/s10750-004-7122-y

Chernetsky AS, Schuttelaars HM, Talke SA (2010) The effect of tidal asymmetry and temporal settling lag on sediment trapping in tidal estuaries. Ocean Dyn 60:1219-1241. https://doi.org/10.1007/ s10236-010-0329-8

De Swart H, Zimmerman J (2009) Morphodynamics of tidal inlet systems. Ann Rev Fluid Mech 41:203-229. https://doi.org/10.1146/ annurev.fluid.010908.165159

Depreiter D, Lanckriet T, Van Holland G, Vanlede J, Beirinckx K, Maris T (2015) Mud disposal and suspended sediment concentration in the Lower Sea Scheldt - towards a hyperturbid system? In: E-procedings of the 36th IAHR World Congress

Dijkstra YM, Brouwer RL, Schuttelaars HM, Schramkowski GP (2017) The iFlow modelling framework v2.4. A modular idealized process-based model for flow and transport in estuaries. Geosci Mod Dev 10:2691-2713. https://doi.org/10.5194/gmd-10-26912017

Dijkstra YM, Schuttelaars HM, Winterwerp JC (2018) The hyperturbid state of the water column in estuaries and rivers: 
the importance of hindered settling. Ocean Dyn 68:377-389. https://doi.org/10.1007/s10236-018-1132-1

Dijkstra YM, Schuttelaars HM, Schramkowski GP, Brouwer RL (2019) Modeling the transition to high sediment concentrations as a response to channel deepening in the Ems River Estuary. J Geophys Res: Oceans 124:1-17. https://doi.org/10.1029/ 2018JC014367

Friedrichs CT, Aubrey DG (1994) Tidal propagation in strongly convergent channels. J Geophys Res: Oceans 99:3321-3336. https://doi.org/10.1029/93jc03219

Friedrichs CT, Wright LD, Hepworth DA, Kim SC (2000) Bottomboundary-layer processes associated with fine sediment accumulation in coastal seas and bays. Cont Shelf Res 20:807-841. https://doi.org/10.1016/s0278-4343(00)00003-0

Godin G (1999) The propagation of tides up rivers with special considerations on the Upper Saint Lawrence River. Estuar Coast Shelf Sci 48:307-324. https://doi.org/10.1006/ecss.1998.0422

IMDC, Deltares, Gems (2007) Uitbreiding studie densiteitsstromingen in de Beneden Zeeschelde in het kader van LTV meetcampagne naar hooggeconcentreerde slibsuspensies. Deelrapport 3 : Valsnelheid slib - INSSEV. Tech. rep., in Dutch

IMDC, Deltares, Svasek Hydraulics, Arcadis (2013a) Instandhouding Vaarpassen Schelde Milieuvergunningen terugstorten baggerspecie. LTV - Veiligheid en Toegankelijkheid Baggeren en storten. Achtergrondrapport A-31. Tech. rep., in Dutch. Available through http://www.vnsc.eu

IMDC, Deltares, Svasek Hydraulics, Arcadis (2013b) Instandhouding vaarpassen Schelde Milieuvergunningen terugstorten baggerspecie. LTV - Veiligheid en Toegankelijkheid. Analyse stortvakken beneden-Zeeschelde. Basisrapport specifieke beheervragen B-23. Tech. rep., in Dutch. Available through http://www. vnsc.eu

Jalón-Rojas I, Schmidt S, Sottolichio A, Bertier C (2016) Tracking the turbidity maximum zone in the Loire Estuary (France) based on a long-term, high-resolution and highfrequency monitoring network. Cont Shelf Res 117:1-11. https://doi.org/10.1016/j.csr.2016.01.017

Jeuken C, Hordijk D, Ides S, Kuijper C, Peeters P, De Sonneville B, Vanlede J (2007) Koploperproject LTV-O\&M - Thema Veiligheid - deelproject 1. Inventarisatie historische ontwikkeling van de hoogwaterstanden in het Schelde estuarium. Tech. Rep. Z4384, WL — Delft Hydraulics, in Dutch

Kandiah A (1974) Fundamental aspects of surface erosion of cohesive soils. PhD Thesis, University of California, Davis

Kromkamp J, Peene J (1995) Possibility of net phytoplankton primary production in the turbid Schelde Estuary (SW Netherlands). Mar Ecol Prog Ser 121:249-259. https://doi.org/10.3354/meps121249

Maris T, Meire P (2017) Onderzoek naar de gevolgen van het Sigmaplan, baggeractiviteiten en havenuitbreiding in de Zeeschelde op het milieu. geïntegreerd eindverslag van het onderzoek verricht in 2016, Tech. Rep. 017-R206, university of antwerp department of ecosystem management (ECOBE), Antwerp, Belgium. in Dutch

Maris T, Cox T, Meire P (2017) Nota wijzigingen in oppervlakte SPM concentraties in de Boven-Zeeschelde. Tech. Rep. 017-R205, University of Antwerp Department of Ecosystem Management (ECOBE), Antwerp, Belgium, in Dutch

Munk WH, Anderson ER (1948) Notes on a theory of the thermocline. J Mar Res 7:276-295

Plancke Y, Van De Moortel I, Hertogs R, Vereecken H, Vos G, Verdoodt N, Meire D, Deschamps M, Mostaert F (2017) Monitoring Effecten Ontwikkelingsschets (MONEOS) - Jaarboek monitoring 2016: Deelrapport 6 - Factual data rapportage van monitoring waterbeweging en fysische parameters in de Zeeschelde in 2016. Versie 4.0. Tech. Rep. 12_070_6, Flanders Hydraulics Research, in Dutch

Talke SA, De Swart HE, Schuttelaars HM (2009) Feedback between residual circulations and sediment distribution in highly turbid estuaries: an analytical model. Cont Shelf Res 29:119-135. https://doi.org/10.1016/j.csr.2007.09.002

Van Braeckel A, Piesschaert F, Van den Bergh E (2006) Historische analyse van de Zeeschelde en haar getijgebonden zijrivieren. 19e eeuw tot heden. Tech. Rep. INBO.R.2006.29, Instituut voor Natuur- en Bosonderzoek, in Dutch

Van Kessel T, Vanlede J, Eleveld M, Van der Wal D (2008) Mud transport model for the Scheldt estuary in the framework of LTV. Tech. rep., Deltares, Flanders Hydraulics, IVM, NIOO

Van Kessel T, Vanlede J (2010) Impact of harbour basins on mud dynamics Scheldt estuary in the framework of LTV. Tech. Rep 1200253-000, Deltares. Flanders Hydraulics

Van Straaten LMJU, Kuenen PH (1957) Accumulation of fine grained sediments in the Dutch Wadden Sea. Netherlands J Geosci 19:329-354

Vandenbruwaene W, Vanlede J, Plancke Y, Verwaest T, Mostaert F (2016) Slibbalans Zeeschelde: Deelrapport 4 - Historische evolutie SPM. Tech. Rep. WL Rapporten 00_029_4, Flanders Hydraulics Research and Antea, Antwerp, Belgium, in Dutch

Vandenbruwaene W, Levy Y, Plancke Y, Vanlede J, Verwaest T, Mostaert F (2017) Integraal plan Boven-Zeeschelde: Deelrapport 8. Sedimentbalans Zeeschelde, Rupel en Durme. Versie 4.0. Tech. Rep. 13_131_8, Flanders Hydraulics, Antwerp, Belgium, in Dutch

Vandenbruwaene W, Stark J (2018) Kunnen simulaties helpen bij het verklaren van de relatie tussen getij en morfologie?, presentation at the Schelde Symposium 2018, available at https://vnsc.eu/uploads/2018/11/rol-simulaties-bij-verklaren-relatietussen-getij-en-morfologie-wouter-vandenbruwaene.pdf. In Dutch

Vanlierde E, Ferket B, Michielsen S, Vereycken K, Van Hoestenberghe T, Levy Y, Plancke Y, Deschamps M, Verwaest T, Mostaert F (2014) MONEOS - jaarboek monitoring WL 2013: Factual data rapportage van monitoring hydrodynamiek en fysische parameters zoals gemeten door WL in het Zeescheldebekken in 2013. Tech. rep. Flanders Hydraulics Research, Antwerp, Belgium, in Dutch

Vanlierde E, Ferket B, Pauwaert Z, Michielsen S, Van De Moortel I, Levy Y, Plancke Y, Meire D, Deschamps M, Verwaest T, Mostaert F (2016) MONEOS - jaarboek monitoring WL 2015. Factual data rapportage van monitoring hydrodynamiek en fysische parameters zoals gemeten door WL in het Zeescheldebekken in 2015 . Versie 3.0. Tech. Rep. 12_070, Flanders Hydraulics Research, in Dutch

Wang XH (2002) Tide-induced sediment resuspension and the bottom boundary layer in an idealized estuary with a muddy bed. J Phys Oceanogr 32:3113-3131. https://doi.org/10.1175/15200485(2002)032<3113:tisrat $>2.0$. co; 2

Winterwerp JC, Wang ZB (2013) Man-induced regime shifts in small estuaries - I: theory. Ocean Dyn 63:1279-1292. https://doi.org/10.1007/s10236-013-0662-9

Winterwerp JC, Wang ZB, Van Brackel A, Van Holland G, Kösters F (2013) Man-induced regime shifts in small estuaries - II: a comparison of rivers. Ocean Dyn 63:1293-1306. https://doi.org/10.1007/s10236-013-0663-8

Publisher's note Springer Nature remains neutral with regard to jurisdictional claims in published maps and institutional affiliations. 